\title{
A BVAR MODEL FOR FORECASTING UKRAINIAN INFLATION AND GDP
}

\author{
NADIIA SHAPOVALENKO ${ }^{a}$ \\ ${ }^{a}$ National Bank of Ukraine \\ E-mail: Nadiia.Shapovalenko@bank.gov.ua
}

\begin{abstract}
In this paper, I examine the forecasting performance of a Bayesian Vector Autoregression (BVAR) model with a steady-state prior and compare the accuracy of the forecasts against the QPM and official NBU forecasts during the Q1 2016-Q1 2020 period. My findings suggest that inflation forecasts produced by the BVAR model are more accurate than those of the QPM model for two quarters ahead and are competitive for a longer time horizon. The BVAR forecasts for GDP growth also outperform those of the QPM but for the whole forecast horizon. Moreover, it is revealed that the BVAR model demonstrates a better performance compared to the NBU's official inflation forecasts over the monetary policy horizon, whereas the opposite is true for GDP growth forecasts. Future research may deal with estimation issues brought about by COVID-19.
\end{abstract}

JEL Codes C30, C53, E37.

Keywords

BVAR, forecast evaluation, inflation forecasting.

Acknowledgments: I extend my gratitude to the National Bank of Ukraine and the Swiss State Secretariat for Economic Affairs for giving me the opportunity to participate in the BCC Research Coaching Programme. In this regard, I would like to thank The Graduate Institute of International and Development Studies for implementing the programme and organizing the presentation for its teacher and students, where I received valuable feedback.

I appreciate the valuable comments of Mr. Cédric Tille, the scientific and programme director of the BCC and Mr. Nikhil Ray, programme manager of the BCC. I extend my gratitude to Dr Fabio Canova, professor of economics at BI Norwegian Business School for his useful comments and guidance.

I also thank the text's reviewers and Andriy Tsapin for providing me with ideas on how to restructure the paper slightly and make some issues more comprehensive.

Disclaimer: The views expressed in this paper are of the author and should not be interpreted as representing the views of the National Bank of Ukraine.

\section{INTRODUCTION}

In 2016, the National Bank of Ukraine moved de facto to an inflation-targeting regime. One of the necessary preconditions for the successful implementation of an inflation-targeting regime is the development of models capable of producing accurate and well-grounded forecasts. In this framework, forecasting inflation becomes an essential task.

Regular medium-term macroeconomic forecasts and monetary policy recommendations at the National Bank of Ukraine (NBU) are mostly based on a Quarterly Projection Model (QPM), which is the main element of the Forecasting and Policy Analysis System (FPAS). The QPM is a semistructural, forward-looking New Keynesian model of a small open economy. Owing to the fact that the main role of the QPM is to produce story-telling and to incorporate some expert judgments, the issue of the forecasts' accuracy may fade into the background. For that reason, it is worth having an additional empirical model producing more accurate forecasts.
The aim of this research is to develop a Bayesian Vector Autoregression (BVAR) model for forecasting inflation and GDP in Ukraine, to examine the forecasting performance of the model, and to compare the accuracy of these forecasts against those of the QPM model and official NBU forecasts.

The forecasting evaluation exercise uses quarterly data for the period of 2016Q1-2020Q1. During this period, the QPM was the main forecasting model, while official NBU forecasts were systematically documented. This allows the forecasts based on BVAR models to be compared with both the QPM and official NBU forecasts.

A Bayesian approach to estimation was chosen given that the Ukrainian data is short and dimensionality problems may arise with the large number of parameters present in the model. The imposition of priors not only solves the dimensionality problem, but supplements the information contained in the data with the personal judgments contained in the prior. Hopefully, the use of different sources of information will sharpen macroeconomic analysis. 
I employ a BVAR model with an informative steady-state prior as in Villani (2009) because this type of priors is widely used for inflation-forecasting in countries that have adopted an inflation-targeting regime, as it explicitly uses information about the inflation target and other equilibrium values.

To the best of my knowledge, I am the first to use a BVAR model with a steady-state prior for forecasting Ukrainian inflation.

The paper is organized as follows. Section 2 contains a literature review. The theoretical framework and some issues regarding the forecast conditioning procedure can be found in Section 3. Section 4 presents an overview of inflation dynamics in Ukraine during the past 15 years. Section 5 describes the data and presents some correlation analysis. Section 6 presents empirical specifications of the models and the priors. Section 7 describes the results and the forecasting performance. Finally, Section 8 offers some concluding remarks. Additional information and results can be found in Appendices A-C.

\section{LITERATURE REVIEW}

The recent forecasting literature points out that among empirical models, BVARs have superior abilities when it comes to forecast output and inflation. In this section, an overview of recent empirical papers using BVAR models for forecasting purposes is provided. The attention is focused on the papers that are using BVARs with steady-state priors.

Villani (2009) was the first who imposed priors directly on the steady state of the model. He argued that this form of priors can be very important, especially for long-term horizon forecasts. Indeed, prior beliefs regarding the steady state are often available in relatively strong form and seem to improve the forecasting ability of the models.

Iversen et al. (2016) compared forecasts made with a DSGE model with a BVAR model against judgmental forecasts published by the Riksbank and found that BVAR model inflation forecasts and the repo rate have outperformed DSGE model forecasts and Riksbank's published forecasts. They also evaluated the usefulness of conditioning information for model-based forecasts (the forecasts were conditioned on the international forecast and the short-term forecast) and found that the difference between conditional and unconditional forecasts is rather small for BVAR forecasts. However, for the DSGE-based forecasts, conditioning information was helpful.

Brázdik and Franta (2017) also came to the conclusion that over the monetary policy horizon, the BVAR approach provides a more precise inflation forecast than the official ones published by the Czech National Bank. In their study, they considered BVAR forecasts, conditioning on the foreign outlook and - for the period of the exchange rate floor also on the officially announced exchange rate and interest rate commitments.

Beechey and Österholm (2010) emphasized that for inflation-targeting countries such as Australia, Canada, New Zealand and Sweden. the out-of-sample forecasts of the mean-adjusted autoregressive model are superior to those of the traditional specification, often by significant amounts.

Clark (2011) showed that a BVAR model with a steadystate prior and stochastic volatility improves the real-time accuracy of density forecasts and modestly improves the accuracy of point forecasts. As he is dealing with the forecasting of U.S. indicators, his model is specified for a closed economy. The endogenous variables are GDP growth, the unemployment rate inflation, the federal funds rate, and the nominal exchange rate. One of the specifications also includes as an endogenous variable the long-term inflation expectation from the Blue Chip Consensus, which is used to measure trend inflation.

The model for the Swedish economy used in Villani (2009) and Iversen et al. (2016) has also foreign indicators and the endogenous variables of the model are foreign GDP growth, foreign inflation, foreign interest rate, domestic GDP growth, domestic inflation, domestic interest rate, and the real exchange rate. The model considered in Iversen et al. (2016) also has nominal wages, hours worked, and the trade-weighted nominal exchange rate instead of the real exchange rate.

The model of Brazdik and Franta (2017) for the Czech economy is similar to the Villani (2009), however it also has a nominal exchange rate instead of a real exchange rate.

To select the specification of a BVAR model for the Ukrainian economy, it is worth starting from the specifications used in the above-mentioned papers.

\section{THE THEORETICAL FRAMEWORK}

\subsection{A BVAR Model with Steady-State Priors}

VAR models are a common tool in empirical macroeconomics, used both in forecasting and for analyzing the impact of shocks to the economy. However, a generous parameterization of the model - together with a small data sample - can result in a poor forecasting performance. Moreover, since the levels at which the forecasts converge are a function of the model's estimated parameters, the forecasting performance at longer horizons may be even worse.

A BVAR with "informative priors" on steady state may be a solution to the problem because it relates the information contained in the data with the judgments about the longrun values of the model's variables. That's in contrast to the majority of BVAR models, which focus on the dynamic behavior of the BVAR model with "informative priors" on steady state deals with the deterministic component of the model.

The methodology was first described by Villani (2009). The author proposes to use a VAR model in a mean adjusted form:

$$
A(L)\left(y_{t}-F x_{t}\right)=\varepsilon_{t},
$$

where $t=1 . . T, y_{t}$ is a $n \times 1$ vector of endogenous variables, $x_{t}$ is a $m \times 1$ vector of exogenous variables, $\varepsilon_{t}$ is i.i.d. $N(0, \Sigma)$, $A(L)=I-A_{1} L-A_{2} L^{2}-\ldots A_{p} L^{p}$ is a $p$ lag polynomial, $A_{1} \ldots A_{p}$ are $n \times n$ matrices, and $F$ is $n \times m$ is a matrix of coefficients for the $m$ exogenous variables. In this framework $F x_{t}$ usually takes the form of a constant, a piecewise constant or a linear time trend.

Taking expectations on both sides of equation and rearranging the equation one has:

$$
E\left(y_{t}\right)=F x_{t},
$$


That is, the long-run value of the variables of the VAR is determined by the model's exogenous component and $F x_{t}$ represents an unconditional mean of $y_{t}$. When the exogenous component includes only constant terms, $F x_{t}$ reduces to a vector of constants so that $E\left(y_{t}\right)=\mu$. Thus, the steady-state values for the data are $\mu$.

$$
y_{t}=A_{1} y_{t-1}+A_{2} y_{t-2}+\ldots+A_{p} y_{t-p}+F x_{t}-A_{1} F x_{t-1}-A_{p} F x_{t-p}+\varepsilon_{t}
$$

After rewriting (3) into transposed form, stacking observations and gathering the regressors into matrices we get:

$$
\begin{aligned}
& \left(\begin{array}{c}
y_{1}^{\prime} \\
y_{2}^{\prime} \\
\vdots \\
y_{T}^{\prime}
\end{array}\right)=\left(\begin{array}{cccc}
y_{0}^{\prime} & y_{-1}^{\prime} & \ldots & y_{1-p}^{\prime} \\
y_{1}^{\prime} & y_{0}^{\prime} & \ldots & y_{2-p}^{\prime} \\
\vdots & \vdots & \ddots & \vdots \\
y_{T-1}^{\prime} & y_{T-2}^{\prime} & \ldots & y_{T-p}^{\prime}
\end{array}\right)\left(\begin{array}{c}
A_{1}^{\prime} \\
A_{2}^{\prime} \\
\vdots \\
A_{p}^{\prime}
\end{array}\right)+ \\
& +\left(\begin{array}{cccc}
x_{1}^{\prime} & -x_{0}^{\prime} & \ldots & -x_{1-p}^{\prime} \\
x_{2}^{\prime} & -x_{1}^{\prime} & \ldots & -x_{2-p}^{\prime} \\
\vdots & \vdots & \ddots & \vdots \\
x_{T}^{\prime} & -x_{T-1}^{\prime} & \ldots & -x_{T-p}^{\prime}
\end{array}\right)\left(\begin{array}{c}
F^{\prime} \\
F^{\prime} A_{1}^{\prime} \\
\vdots \\
F^{\prime} A_{p}^{\prime}
\end{array}\right)+\left(\begin{array}{c}
\varepsilon_{1}^{\prime} \\
\varepsilon_{2}^{\prime} \\
\vdots \\
\varepsilon_{T}^{\prime}
\end{array}\right)
\end{aligned}
$$

Or in compact notation:

$$
Y=X B+Z \Delta+E,
$$

where

$$
\begin{aligned}
Y & =\left(\begin{array}{c}
y_{1}^{\prime} \\
y_{2}^{\prime} \\
\vdots \\
y_{T}^{\prime}
\end{array}\right), X=\left(\begin{array}{cccc}
y_{0}^{\prime} & y_{-1}^{\prime} & \ldots & y_{1-p}^{\prime} \\
y_{1}^{\prime} & y_{0}^{\prime} & \ldots & y_{2-p}^{\prime} \\
\vdots & \vdots & \ddots & \vdots \\
y_{T-1}^{\prime} & y_{T-2}^{\prime} & \ldots & y_{T-p}^{\prime}
\end{array}\right), \\
B & =\left(\begin{array}{c}
A_{1}^{\prime} \\
A_{2}^{\prime} \\
\vdots \\
A_{p}^{\prime}
\end{array}\right), Z=\left(\begin{array}{cccc}
x_{1}^{\prime} & -x_{0}^{\prime} & \ldots & -x_{1-p}^{\prime} \\
x_{2}^{\prime} & -x_{1}^{\prime} & \ldots & -x_{2-p}^{\prime} \\
\vdots & \vdots & \ddots & \vdots \\
x_{T}^{\prime} & -x_{T-1}^{\prime} & \ldots & -x_{T-p}^{\prime}
\end{array}\right), \\
& \\
\Delta & =\left(\begin{array}{c}
F^{\prime} \\
F^{\prime} A_{1}^{\prime} \\
\vdots \\
F^{\prime} A_{p}^{\prime}
\end{array}\right), E=\left(\begin{array}{c} 
\\
\varepsilon_{2}^{\prime} \\
\vdots \\
\varepsilon_{T}^{\prime}
\end{array}\right)
\end{aligned}
$$

Vectorizing (4) and compactly rewriting it we obtain:

$$
y=\bar{X} \beta+\bar{Z} \delta+\epsilon,
$$

where

$$
\begin{aligned}
& y=\operatorname{vec}(Y), \bar{X}=I_{n} \otimes X, \beta=\operatorname{vec}(B), \bar{Z}=I_{n} \otimes Z, \\
& \delta=\operatorname{vec}(\Delta), \epsilon=\operatorname{vec}(E) .
\end{aligned}
$$

Let:

$$
\begin{gathered}
\operatorname{vec}\left(\Delta^{\prime}\right)=\operatorname{vec}\left(F A_{1} F \ldots A_{p} F\right)= \\
=\left(\begin{array}{c}
I_{n m} \\
I_{m} \otimes A_{1} \\
\vdots \\
I_{m} \otimes A_{p}
\end{array}\right) \operatorname{vec}(F)=U \psi
\end{gathered}
$$

where $\psi=\operatorname{vec}(F)$,

$$
U=\left(\begin{array}{c}
I_{n m} \\
I_{m} \otimes A_{1} \\
\vdots \\
I_{m} \otimes A_{p}
\end{array}\right)
$$

Note that there are now three blocks to estimate $-\beta$, which corresponds to the coefficients on the endogenous variables $y_{t} ; \psi$, which corresponds to coefficients on the exogenous variables $x_{t}$ and $\Sigma$ - the residual variancecovariance matrix.

A diffuse prior for the error covariance matrix is assumed, while the prior on the other two sets of coefficients is normal.

$$
\begin{gathered}
p(\Sigma) \propto|\Sigma|^{-(n+1) / 2}, \\
\beta \sim \mathrm{N}\left(\beta_{0}, \Omega_{0}\right), \\
\psi \sim \mathrm{N}\left(\psi_{0}, \Lambda_{0}\right),
\end{gathered}
$$

Dieppe et al. (2016) argue that one can't set a flat prior for $\psi$ as in the Minnesota scheme, because the very purpose of this type of prior is to add information about means into the estimation process. It is recommended to specify a subjective $95 \%$ probability interval for the prior values. Using the properties of the normal distribution, the prior mean of the distribution is determined as the mode of the specified subjective $95 \%$ probability interval, while the variance is obtained by the fact that the bounds of a subjective 95\% probability interval are located at 1.96 standard deviations from the mean.

Villani (2009) shows the complete derivation of the posterior distribution. The steps of a Gibbs sampling algorithm for the BVAR with a steady-state prior can be found in Appendix A.

\subsection{Hyperparameter Values}

Many researchers obtain the optimal hyperparameters by maximizing the marginal likelihood over a grid of possible values. They include Del Negro and Schorfheide (2004), Schorfheide and Song (2015) and Carriero, Clark, and Marcellino (2015). The grid-search approach is also represented in the Bayesian Estimation, Analysis and Regression (BEAR) MATLAB toolbox developed by the European Central Bank (Dieppe et al (2016)).

However, being suitable for low-dimensional models, it may be computationally infeasible for higher dimensions. Therefore, more inference-based approaches to setting the hyperparameter have arisen. Giannone et al. (2012) use a hierarchical modeling framework.

Gustafsson, Villani and Stockhammar (2020) propose a new Bayesian optimization method. They focus on the common situation of maximizing a marginal likelihood evaluated by MCMC, where the precision is determined by the number of MCMC iterations. The authors argue that "the ability to choose the precision makes it possible for the algorithm to take occasional cheap and noisy evaluations to explore the marginal likelihood surface, thereby finding the optimum faster".

Chan et al (2019) apply Automatic Differentiation (AD) to calculate the gradient of the marginal likelihood with respect to the hyperparameters, which is then used as an input in an optimization routine. Authors claim that by computing the gradient efficiently using $A D$, the proposed method is substantially faster than the conventional grid-search approach. 
To put it in a nutshell, the variety of methods is aimed at increasing the speed of finding the optimum. Whereas, they consider the same criterion, which is the maximization of marginal likelihood, which - according to Giannone et al. (2012) - "corresponds to maximizing the one-step-ahead, outof-sample forecasting ability" of the model. In order to care more about the forecasting accuracy for the monetary policy horizon, it is probably worth trying to choose hyperparameters by maximizing the forecasting performance for 4-6 quarters over a presample. However, taking into account the smal sample and low dimensionality of the models used in the research, a simple grid search was applied.

The procedure of the estimation of hyperparameters is the following. First, a range for each hyperparameter is specified, together with a step size defining the size of the increment within the range. Then the marginal likelihood is estimated for each model with every possible combination of hyperparameter values. The optimal combination, which is the one that maximizes the marginal likelihood, is then kept.

\subsection{Forecasting}

Iterated BVAR forecasts for up to six quarters ${ }^{1}$ are simulated in the form of a posterior predictive distribution. The root mean squared error (RMSE) is used to evaluate the accuracy of the BVAR point predictions and to compare it against the QPM model and the NBU official forecasts. Also, a simple AR model is constructed to serve as a benchmark (the lag length of the AR model is selected minimizing the RMSE within the forecasting exercise period).

Together with unconditional forecasts, I compute forecasts conditioning on foreign indicators. I do so for a number of reasons. First, almost all mid-term forecasts at the NBU are based on some assumptions concerning either external or internal factors (e.g., conditioning on the interest rate, as it serves as a main instrument of monetary policy; or on external variables, as more precise forecasts of external indicators are available). Hence, conditioning allows forecasts to be more realistic. Moreover, it makes the interpretation of forecasts and story building around it easier. Second, conditioning on the same variables used in the QPM makes the comparison of the models more meaningful. Finally, I expect the conditional inflation forecast to be more precise and I am going to examine this hypothesis.

There are several options in the literature on how to incorporate external information into the forecasts of BVAR. The hard conditioning option was developed by Waggoner and Zha (1999), who derived a Gibbs sampling algorithm to construct the posterior predictive distribution of the conditional forecast.

A more efficient solution was suggested by Jarocinski (2010). In this framework, shocks are divided into constructive and non-constructive. Constructive shocks are the shocks on which a condition is imposed. However, conditioning may not be unique, meaning the same condition may be imposed on different shocks. Therefore, the researcher should carefully select the shocks generating the constraint, in order to produce sensible economic results.

In contrast to hard conditioning, in which the future values of variables are fixed at single points, soft conditioning is more flexible and deals with conditions that only restrict the future values within a certain range. Soft conditioning was also introduced by Waggoner and Zha (1999). However, an alternative methodology (entropic tilting) initially proposed by Robertson et al. (2005) and further developed by Krüger et al. (2017) allows for incorporating external information into model-based forecasts.

Comparing the soft conditioning by Waggoner and Zha (1999) with entropic tilting, Dieppe et al. (2016) argue that one of the main advantages of entropic tilting is its high flexibility. This is because the method of Waggoner and Zha (1999) only allows to set the center of the predictive distribution, whereas the entropic tilting method allows any moment associated with the distribution to be determined, along with quantile values.

The main idea of the entropy tilting method is to change the initial predictive distribution of the unconditional forecast to a new one that satisfies specified moment conditions, and to minimize the distortions in the other properties of the new distribution. In other words, to get a new distribution, one minimizes the relative entropy between the two distributions, subject to the restriction that the new distribution satisfies the specified moment conditions. So, by construction, conditional forecasts obtained through entropic tilting are as close to the initial distribution of unconditional forecast as possible. Further details on the technical implementation of entropic tilting can be found in Dieppe et al. (2016).

In this paper I use entropic tilting, presuming that it will produce more accurate forecasts.

\section{INFLATION IN UKRAINE, AN OVERVIEW}

During the Great Recession, Ukraine was hit by a sharp terms-of-trade shock: steel prices plunged (in 2008 steel represented about $40 \%$ of exports and $15 \%$ of GDP), while energy import prices remained high due to the phasing out of Russia's natural gas subsidies. The materialization of trade shock terms had a considerable impact on the real sector. In addition, major strains were building up in the banking system following a system-wide run on deposits. A loss of confidence domestically led to capital flight out of the hryvnia into foreign exchange cash. Altogether, this led to a massive devaluation of the currency, plummeting real GDP and a shrinking of the current account deficit in 2009.

In 2010-2011, the economy started recovering, inflation declined to single digits, the exchange rate was stabilized, and growth rebounded. In 2012-2013, inflation approached zero due to weak economic activity (annual GDP growth was $0.2 \%$ in 2012 and $0.0 \%$ in 2013). Keeping the exchange rate stable led to the accumulation of huge imbalances in the economy. In 2014, these imbalances - along with the military conflict in the east of the country - led to a severe economic crisis, with real GDP falling by $10 \%$ in 2015 , with sharp depreciation of the hryvnia and inflation reaching its peak of almost 60\% year-over-year in the spring of 2015 .

It is worth noting that the nature of the two high inflation episodes (2008 and 2015) is different: the second inflationary spike was caused by the pass through of the hryvnia devaluation, whereas in 2008 , rising inflation was a sign that the economy had been overheating. 

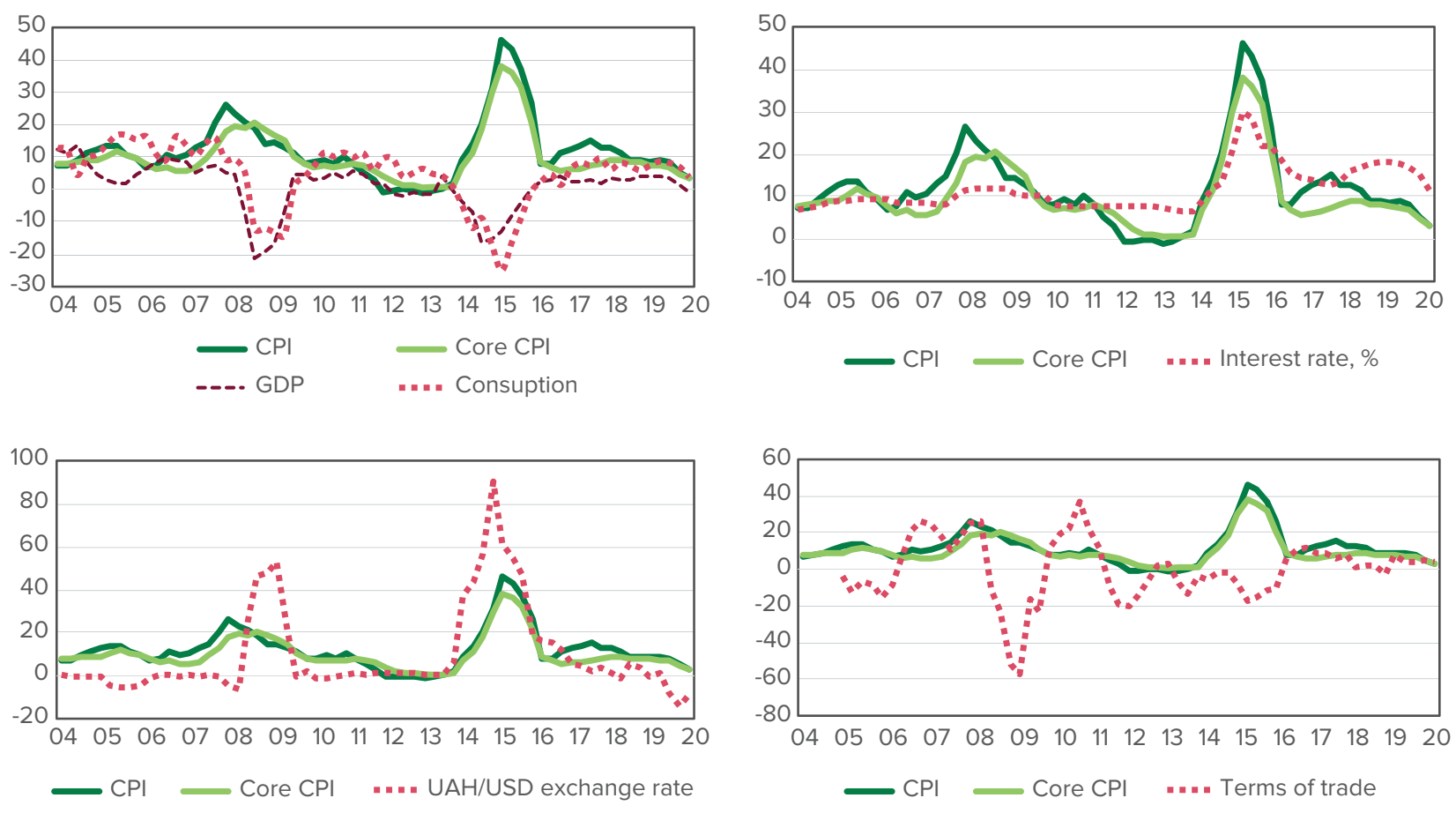

$\longrightarrow \mathrm{CPI} \longrightarrow$ Core CPI \#... Terms of trade

Figure 1. Main Economic Indicators, yoy, in logs

In August 2015, the NBU declared a transition to the inflation-targeting regime in order to break the upward inflationary trend and stabilize the economy. De facto, it moved to the inflation-targeting regime in 2016. The NBU announced it set its mid-term inflation target (year-over-year CPI growth) at $5 \%$ and to be achieved gradually in the following stages:

$12 \%+/-3$ ppts as of the end of 2016 ;

$8 \% \pm 2$ ppts as of the end of 2017

$6 \% \pm 2$ ppts as of the end of 2018 ;

$5 \% \pm 1 \mathrm{ppt}$ as of the end of 2019 and further on.

It is well-known that the inflation targeting regime uses the policy rate as a main instrument. To bring inflation down to the target, the NBU should increase the interest rate to moderate demand and to cool inflationary pressure. Therefore, the gradual strategy of bringing inflation to its target was chosen deliberately in order to minimize the costs of disinflation for economic growth.

In general, the process of disinflation, which started in 2016, went well. In 2019, consumer price inflation gradually declined to a six-year low of $4.1 \%$. Therefore, the NBU finally achieved its target of $5 \% \pm 1$ ppt. The average GDP growth was $2.8 \%$ in $2016-2019$.

2020 brought a new challenge: the COVID-19 pandemic was a shock of unprecedented global severity affecting all areas of the economy. In this situation, swift and reasonable policy measures have been of great importance. In the near future, policy makers will need to find the right balance between supporting the economy using an accommodating policy and maintaining price stability.

To summarize, the recent economic developments in Ukraine show that along with domestic conditions, external

ones are another important driver of inflation and should be used to forecast Ukrainian inflation.

\section{DATA DESCRIPTION AND CORRELATIONS ANALYSIS}

Although the methodology of meta-analysis is helpful I use quarterly foreign data, national accounts data, prices and exchange rates over the period of 2004Q1-2020Q1 (see Table B.1, Appendix B). Alternative measures of different variables are employed in order to find the one with the highest predictive power for inflation:

- In addition to weighted CPI, PPI is used for foreign price levels;

CPI and PPI deflator-based REER ${ }^{2}$ are used for the real exchange rate;

vernight or 3-month LIBOR is used as the foreign interest rate;

Various commodity prices are employed as an alternative for foreign price levels;

I use two measures of terms of trade, constructed as the ratio between the index of export prices and the index of import prices for (1) goods, (2) most important groups of raw commodities;

Monetary aggregate $\mathrm{M} 2$, nominal and real wage are used to reflect domestic factors.

All the data except interest rates are measured in natural logarithms. Growth variables in annualized quarter-over quarter terms are used. To choose the variable to be used in the forecasting exercise, I employed a simple correlation analysis. The figures - as well as the correlation coefficients between Ukrainian CPI, GDP and other variables - are presented in Figure C1, Appendix C.

\footnotetext{
2 To construct a weighted measure of foreign indicators, 3 sets of countries-trading partners were used. The first one contains 5 countries: Euro Area, United States, Russian Federation, China and Turkey. The second index consists only of Euro Area, United States, Russian Federation to simplify the assumptions on the external sector behavior. The third one, has data for 40 countries. However, only weighted real GDP and CPI are available for this broader set of countries.
} 
The CPI is significantly correlated with both the inflation differential of trading partners and the NEER. However, there is no significant correlation of CPI with the weighted GDP of trading partners and various commodity prices, as these indicators may be more important for domestic production rather than consumption. CPI has a very weak negative correlation with the lagged policy rate, whereas the contemporaneous correlation has a positive sign. This can be explained by the fact that the interest rate hadn't been used as an instrument prior to 2016 (before the implementation of inflation-targeting). So the monetary transmission mechanism didn't work as it was supposed to.

In addition to unconditional correlations, correlations conditioned on the policy rate were analyzed. However, no serious differences with unconditional correlations were found (see Figure C.2, Appendix C). Domestic GDP is significantly correlated with foreign GDP, which means that for such a small open economy as Ukraine's, external demand is an important factor of GDP growth. The positive correlation of GDP with terms of trade and commodity prices reflects the fact that these indicators drive the Ukrainian business cycle, with Ukraine being a commodity net exporter.

For the same reason as with $\mathrm{CPI}$, the correlation of GDP with the policy rate is weak. The correlation between monetary aggregates and wages suggests not to include them into the model.

To conclude, taking into account the results of the correlation analysis, together with the stylized facts from the Section 4 and the models described in the literature review, the following indicators were chosen for the BVAR model for the Ukrainian economy: the weighted ${ }^{3}$ GDP of trading partners, the weighted inflation differential of trading partners, domestic GDP, domestic CPI, the domestic policy rate, the nominal effective exchange rate (NEER), and the terms of trade, constructed as the ratio of the most important groups of raw commodities and the non-energy commodity price index.

\section{EMPIRICAL MODEL SPECIFICATIONS AND THE PRIORS}

The selection of the variables for the model is based not only on correlations between the variables and is conducted in several steps. First, I analyzed the variables that were selected in other research papers (Villani (2009) and Iversen et al. (2016) for the Swedish economy, Brazdik and Franta (2017) for the Czech economy). Second, I described the recent economic developments in Section 4 with the purpose to better understand the relationships between macroeconomic variables and the main transmission channels in Ukraine. Finally, the correlation analysis was helpful in distinguishing between alternative measures of some economic variables.

The benchmark BVAR specification (MB) for Ukraine is the following:

$$
\mathrm{y}_{t}=\left(\Delta g d p_{t}^{f}, \pi_{t}^{f}, \Delta g d p_{t}, \pi_{t}, i_{t}, \text { neer }_{t}\right)^{\prime}
$$

$y_{t}$ includes foreign GDP growth $\left(\Delta g d p^{f}\right)$, foreign inflation $\left(\pi^{f}\right)$, domestic GDP growth $(\Delta g d p)$, domestic inflation $(\pi)$, domestic interest rate (i), and the NEER (neer).

In order to find the best possible set of variables, two additional specifications are considered (MA_p and MA_tot):

$$
\mathrm{y}_{t}=\left(\Delta g d p_{t}^{f}, \text { wbnonen }_{t}, \Delta g d p_{t}, \pi_{t}, i_{t}, \text { neer }_{t}\right)^{\prime}
$$

$y_{t}$ includes non-energy commodity price index (wbnonen) instead of foreign inflation $\left(\pi^{f}\right)$.

$$
\mathrm{y}_{t}=\left(\Delta g d p_{t}^{f}, \pi_{t}^{f}, \Delta g d p_{t}, \pi_{t}, i_{t}, \text { neer }_{t}, \text { tot }_{t}\right)^{\prime}
$$

in addition to the variables from the benchmark model, $y_{t}$ includes terms of trade (tot).

In order to take into account that Ukraine is a small open economy, foreign variables and terms of trade are treated as block exogenous. Namely, the block submatrices in $A(L)$, corresponding to the effects of domestic variables on foreign ones, are set to zero.

Standard lag length criteria were used to select the lag length (see Table B.2, Appendix B). Different criteria suggest the use of lags from 1 up to 5 . In general, specifications with, larger lag length were preferred. As a robustness check, more parsimonious specifications with two lags were also estimated and the results didn't significantly differ.

The hyperparameters for the models are set according to the results of grid search procedure (information regarding the grid search is in Table B.3, Appendix B). The values of hyperparameters, used as well as the information regarding number of lags and the number of iterations, is presented in Table 1.

Table 1. Hyperparameters and Lags

\begin{tabular}{l|c|c|c}
\hline & MB & MA_P & MA_TOT \\
\hline Autoregressive coefficient & 0.5 & 0.4 & 0.4 \\
Overall tightness $\left(\lambda_{1}\right)$ & 0.2 & 0.2 & 0.2 \\
Cross-variable weighting $\left(\lambda_{2}\right)$ & 1 & 0.9 & 1 \\
Lag decay $\left(\lambda_{3}\right)$ & 1 & 1 & 1 \\
block exogeneity shrinkage $\lambda_{5}:$ & 0.001 & 0.001 & 0.001 \\
total number of iterations: & 10,000 & 10,000 & 10,000 \\
bum-in iterations: & 5,000 & 5,000 & 5,000 \\
Lag length & 3 & 4 & 5 \\
\hline
\end{tabular}

The priors on the steady states are normally distributed. In order to account for changes in the monetary policy regime (the move to inflation targeting in 2016), two different sets of priors are employed. The first regime covers the period from 2004Q1 up to 2015Q4 and the second regime starts at 2016Q1.

To specify the moments of the prior distribution values, Dieppe et al (2016) recommend first to set a subjective 95\% probability interval, and then calculate the mean and variance for each variable. Brazdik and Franta (2017), on the contrary, suggest calculating a 95\% probability interval, based on the mean and variance.

\footnotetext{
${ }^{3}$ Aggregated foreign indicators for 40 countries were chosen.
} 
I follow Brazdik and Franta (2017). The means of the priors are taken from the trends estimated in the QPM model. Variances are set using the information from other studies, keeping in mind that tighter interval would imply smaller prior variance and hence greater confidence that the steady-state value corresponds to the specified prior mean. On the other hand, a wider interval would imply larger prior variance and more weight given to the data.

The CPI prior for the 2nd regime is set in a different manner. Since in the inflation-targeting regime both target and the bounds for inflation are known, the bounds are used directly to set the values for a $95 \%$ interval. The means and variances from Villani (2009) and Brazdik and Franta (2017) are in Tables B.4 and B.5, Appendix B. Steady state priors for the Ukrainian model are presented in Table 2. In general, priors for Ukrainian model are looser than those for the Swedish model and tighter than those for the Czech model.

\section{ESTIMATION RESULTS AND FORECASTING PERFORMANCE}

\subsection{Estimation Results}

The priors and posterior estimates of the steady state for BVAR models are presented in Table 3. The estimates of the steady states are based on the reduced-form VAR, hence structural shock identification does not play any role. Impulse responses based on recursive identification can be found in Figures C.3-C.5, Appendix C.

Specifically, priors are reported for the 2nd regime, while posterior estimates are presented for 2020Q1 (which

Table 2. Steady State prior Distributions corresponds to the end of the sample, so that the full data set was used for the estimation).

There are some differences between the prior and posterior medians of the steady state for 2020Q1, as well as differences in the values of the posterior medians of three BVAR models that are worth discussing.

All three models have lower posterior medians for foreign GDP and CPI than the prior median value. However, for the MB model, this difference is more pronounced. The reason for the difference may be the fact that in contrast to MB model, both the MA_P and MA_TOT models contain additional information on the dynamics of commodity prices, which may influence the steady state values of foreign variables.

Lower steady state values of external demand in the MB model, in turn, affect domestic GDP growth. Hence, the posterior medians for the domestic variables of the MB model suggest lower steady-state value of GDP growth, inflation, the policy rate and a more pronounced NEER depreciation trend.

\subsection{Forecasting Performance}

In this subsection, the forecasting performance of the BVAR models is examined. The RMSE is employed as the measure of forecasting performance. In addition to RMSE, the equal forecasting accuracy of the models is statistically evaluated using the Diebold-Mariano test. The comparison is divided into four stages. During the first stage, the unconditional forecasts of MB, MA_P and MA_TOT are compared to the forecasts of the AR1 model.

\begin{tabular}{l|c|c|c|c|c|c|c|c}
\hline & \multicolumn{3}{|c|}{ regime 1: 2004q1 2015q4 } & \multicolumn{4}{c}{ regime 2: 2016q1 2020q1 } \\
\hline & Mean & Var & $95 \%$ & Interval & Mean & Var & $95 \%$ & Interval \\
\hline GDPW & 4.0 & 0.5 & 3.0 & 5.0 & 3.0 & 0.5 & 2.0 & 4.0 \\
CPIW & 6.0 & 0.5 & 5.0 & 7.0 & 3.5 & 0.5 & 2.5 & 4.5 \\
GDPUA & 1.0 & 1.0 & -1.0 & 3.0 & 2.0 & 0.5 & 1.0 & 3.0 \\
CPIUA & 11.0 & 2.0 & 7.1 & 14.9 & 8.0 & 1.0 & 6.0 & 10.0 \\
\hline IUA & 12.5 & 0.7 & 11.1 & 13.9 & 11.0 & 0.6 & 9.8 & 12.2 \\
NEER & -6.8 & 2.0 & -10.7 & -2.9 & -2.5 & 1.0 & -4.5 & -0.5 \\
TOT & -2.0 & 1.0 & -4.0 & 0.0 & 3.0 & 0.5 & 2.0 & 4.0 \\
PNONEN & 6.0 & 1.0 & 4.0 & 8.0 & 1.0 & 0.5 & 0.0 & 2.0 \\
\hline
\end{tabular}

Table 3. Priors and Posterior Estimates for 2020q1

\begin{tabular}{l|c|c|c|c|c|c|c|c|c|c|c|c}
\hline & \multicolumn{2}{|c|}{ Prior, 2016q1 2020q1 } & \multicolumn{3}{c|}{ Posterior, MB } & \multicolumn{3}{c|}{ Posterior, MA_P } & \multicolumn{3}{c}{ Posterior, MA_TOT } \\
\hline & Median & $95 \%$ & Interval & Mean & Var & Interval & Median & $95 \%$ & Interval & Median & $95 \%$ & Interval \\
\hline GDPW & 2.0 & 3.0 & 4.0 & 2.7 & 1.9 & 3.7 & 1.8 & 2.7 & 3.6 & 1.8 & 2.7 & 3.6 \\
CPIW & 2.5 & 3.5 & 4.5 & 3.4 & 2.6 & 4.2 & & & & 2.5 & 3.3 & 4.0 \\
\hline GDPUA & 1.0 & 2.0 & 3.0 & 2.0 & 1.1 & 3.0 & 1.0 & 2.0 & 3.0 & 1.1 & 2.1 & 3.0 \\
CPIUA & 6.0 & 8.0 & 10.0 & 7.8 & 5.9 & 9.7 & 5.6 & 7.5 & 9.5 & 5.7 & 7.7 & 9.6 \\
IUA & 9.8 & 11.0 & 12.2 & 11.8 & 10.7 & 13.0 & 10.7 & 11.9 & 13.0 & 10.7 & 11.9 & 13.0 \\
NEER & -4.5 & -2.5 & -0.5 & -23 & -42 & -0.3 & -4.4 & -2.4 & -0.4 & -4.4 & -2.3 & -0.4 \\
\hline TOT & 2.0 & 3.0 & 4.0 & & & & & & & 2.0 & 3.0 & 4.0 \\
PNONEN & 0.0 & 1.0 & 2.0 & & & & 0.1 & 1.1 & 2.0 & & & \\
\hline
\end{tabular}


Then, during the second stage, the forecasts of the BVAR model with the most accurate unconditional forecasts are compared with the forecasts of the same model, conditioned on external indicators - namely, foreign GDP growth and foreign inflation - in order to examine whether conditioning improves forecasting accuracy.

At the following stage, the conditional forecasts of the best model from the second stage are compared with the conditional forecasts of the QPM model.

Finally, at the fourth stage, conditional forecasts of the best BVAR model are transformed from annualized quarterover-quarter indicators into year-over-year indicators and compared with official NBU forecasts. The data transformation is necessary because NBU forecasts are only available on a year-over-year basis.

Because the forecasting performance for inflation at the monetary policy horizon is of most interest, I focus attention on the forecast horizons from the fourth to sixth quarters.

Table 4. RMSEs for Unconditional Forecasts Relative to the AR1 Model

\begin{tabular}{c|c|c|c|c|c|c}
\hline & \multicolumn{3}{|c|}{ CPI } & \multicolumn{3}{c}{ GDP } \\
\hline period & MB & MA_P & $\begin{array}{c}\text { MA } \\
\text { TOT }\end{array}$ & MB & MA_P & $\begin{array}{c}\text { MA } \\
\text { TOT }\end{array}$ \\
\hline 1 & 1.05 & 1.02 & 1.05 & 0.89 & 0.99 & 0.89 \\
2 & 1.02 & 1.02 & 0.93 & $0.51^{* *}$ & $0.44^{* *}$ & $0.48^{* *}$ \\
3 & 1.11 & 1.15 & 1.11 & $0.51^{* *}$ & $0.50^{* *}$ & $0.52^{* *}$ \\
4 & 1.04 & 1.02 & 0.97 & $0.67^{* *}$ & $0.59^{* *}$ & $0.60^{* *}$ \\
5 & $0.73^{*}$ & $0.75^{*}$ & $0.64^{* *}$ & $0.74^{*}$ & $0.67^{* *}$ & $0.73^{* *}$ \\
6 & $0.72^{*}$ & $0.69^{* *}$ & $0.67^{* *}$ & 0.83 & $0.75^{* *}$ & $0.82^{*}$ \\
\hline
\end{tabular}

Note: Asterisks indicate that according to the Diebold-Mariano test, the difference in forecasting performance relative to the AR1 model is statistically significant at $5 \%$ or $10 \%$ level ${ }^{* *}$ and * respectively).

The forecast accuracy of the unconditional BVAR forecasts with different variable specifications is reported in Table 4. Plots of the forecasts can be found in Figure C.6, Appendix C. RMSE values are shown relative to those of an AR1 model in order to facilitate the comparison. Therefore, for the given model, a value below unity means it's better than the AR1 model's precision.

Regarding CPI, the BVAR model - which includes terms of trade (MA_TOT) - seems to have the best forecasting accuracy and outperforms AR1 at the horizon of interest. It is worth noting that in the short run, AR1 forecasts are more accurate. However, the difference is not statistically significant.

Regarding GDP, the BVAR models outperform the AR1 model from 2 nd to 6 th quarters and the differences are statistically significant. The added prior information may be the reason for the superior performance of the BVAR models at the longer horizons.

Since the BVAR model, which includes terms of trade (MA_TOT), has lower RMSE for inflation. It will be used in further comparison.

The value of incorporating external conditioning information can be judged by comparing the RMSE for the conditional and the unconditional BVAR forecasts (see Table 5).
Regarding CPI, on average, conditional forecasts are more accurate than unconditional ones, but the difference is rather small. For GDP, unconditional forecasts perform better than the conditional ones, still the difference is not significant.

Hence, I may conclude that adding external information probably does not play an important role in improving the forecasting accuracy of inflation and GDP.

Table 6 shows the results of the third stage (see also Figure C.7, Appendix C). For CPI inflation, the BVAR forecasts are superior for 4th and 6th quarters, while the RMSE of the QPM forecasts for 5 th quarter is lower than that of the BVAR. Also, for the 1st quarter, both the BVAR and the QPM are inferior to the AR1.

The results are better for GDP. Both the BVAR and the QPM forecasts beat AR1 forecasts starting from the 2nd quarter, although not all differences are statistically significant. For the whole horizon, GDP forecasts of the BVAR model are more accurate than those of the QPM model.

Therefore, in general, for both inflation and GDP growth, the BVAR model forecasts are competitive at minimum, if not better than QPM forecasts.

The forecasting performance of the BVAR and official NBU forecasts for year-over year indicators is compared in Table 7. Plots of the forecasts can be found in Figure C.8, Appendix C.

Table 5. RMSEs for the Unconditional and Conditional Forecasts of MA_TOT Relative to the AR1 Model

\begin{tabular}{c|c|c|c|c}
\hline & \multicolumn{2}{|c|}{ CPI } & \multicolumn{2}{c}{ GDP } \\
\hline$q$ & $\begin{array}{c}\text { MA_TOT } \\
\text { (cond) }\end{array}$ & MA_TOT & $\begin{array}{c}\text { MA_TOT } \\
\text { (cond) }\end{array}$ & MA_TOT \\
\hline 1 & 1.07 & 1.05 & 0.89 & 0.89 \\
2 & $0.83^{*}$ & 0.93 & $0.79^{*}$ & $0.48^{* *}$ \\
\hline 3 & 1.02 & 1.11 & $0.72^{* *}$ & $0.52^{* *}$ \\
4 & $0.83^{*}$ & 0.97 & 0.83 & $0.60^{* *}$ \\
5 & $0.78^{* *}$ & $0.64^{* *}$ & 0.91 & $0.73^{* *}$ \\
6 & $0.66^{* *}$ & $0.67^{* *}$ & $0.82^{*}$ & $0.82^{*}$ \\
\hline
\end{tabular}

Note: Asterisks indicate that according to the Diebold-Mariano test, the difference in the forecasting performance - relative to the AR1 model - is statistically significant at $5 \%$ or $10 \%$ level (** and * respectively).

Table 6. RMSEs of Conditional Forecasts Relative to the AR1 Model

\begin{tabular}{c|c|c|c|c}
\hline & \multicolumn{2}{|c|}{ CPI } & \multicolumn{2}{c}{ GDP } \\
\hline$q$ & $\begin{array}{c}\text { MA_TOT } \\
\text { (cond) }\end{array}$ & QPM & $\begin{array}{c}\text { MA_TOT } \\
\text { (cond) }\end{array}$ & QPM \\
\hline 1 & 1.07 & 1.17 & 0.89 & 1.04 \\
\hline 2 & $0.83^{*}$ & 1.18 & $0.79^{*}$ & $0.84^{*}$ \\
3 & 1.02 & 0.95 & $0.72^{* *}$ & 0.97 \\
4 & $0.83^{*}$ & 0.89 & 0.83 & 0.89 \\
5 & $0.78^{* *}$ & 0.74 & 0.91 & 0.95 \\
\hline 6 & $0.66^{* *}$ & $0.69^{* *}$ & $0.82^{*}$ & 0.88 \\
\hline
\end{tabular}

Note: Asterisks indicate that according to the Diebold-Mariano test, the difference in forecasting performance relative to the AR1 model is statistically significant at $5 \%$ or $10 \%$ level (** and * respectively). 
Table 7. RMSEs of the Forecasts for the Indicators on a Year-over-Year Basis

\begin{tabular}{c|c|c|c|c}
\hline & \multicolumn{2}{|c|}{ CPI } & \multicolumn{2}{c}{ GDP } \\
\hline $\mathrm{q}$ & $\begin{array}{c}\text { MA_TOT } \\
\text { (cond) }\end{array}$ & NBU & $\begin{array}{c}\text { MA_TOT } \\
\text { (cond) }\end{array}$ & NBU \\
\hline 1 & 1.07 & 0.99 & 0.89 & 1.02 \\
2 & 0.95 & 0.85 & $0.74^{* *}$ & 0.87 \\
3 & 0.90 & 0.90 & $0.59^{* *}$ & $0.68^{* *}$ \\
4 & 0.82 & 0.88 & $0.52^{* *}$ & $0.60^{* *}$ \\
5 & $0.64^{*}$ & 0.92 & $0.62^{* *}$ & $0.36^{* *}$ \\
6 & $0.55^{* *}$ & 0.85 & $0.66^{* *}$ & $0.52^{* *}$ \\
\hline
\end{tabular}

Note: Asterisks indicate that according to the Diebold-Mariano test, the difference in forecasting performance relative to the AR1 model is statistically significant at $5 \%$ or $10 \%$ level (** and * respectively).

Regarding CPI, the BVAR forecasts outperform the official NBU forecasts at the horizon of interest. However, in the short run, the official NBU forecasts are the most accurate: they beat both the BVAR and AR1 forecasts. This finding could be a consequence of the fact that the NBU is considering a broader information set during the forecasting process and different types of models specifically designed for short-run forecasting. Moreover, $\mathrm{CPI}$ is forecasted at the disaggregated level and for some groups of prices (e.g. administrative prices), expert judgments are included.

Regarding GDP, NBU forecasts have a better performance than BVAR forecasts at the horizon of interest, probably because GDP components are treated separately and expert knowledge is included (for example, the BVAR model doesn't explicitly have variables reflecting fiscal policy stance).

To conclude, the BVAR forecasts of inflation outperform the official NBU forecasts at the horizon of interest, whereas the opposite is true for the forecasts of GDP growth.

An interesting perspective can be added if we look at the forecast bias. The forecast bias is measured as the average forecast error at a certain horizon. In turn, the forecast error is calculated as the difference between the actual value and forecasted one. A non-zero bias indicates a possible persistent difference between the forecasts and the observed values.

Table 8. Forecast Bias (CPI)

\begin{tabular}{|c|c|c|c|c|c|c|}
\hline & \multicolumn{6}{|c|}{ CPI } \\
\hline$q$ & $\mathrm{MB}$ & MA_P & $\begin{array}{l}\text { MA } \\
\text { TOT }\end{array}$ & $\begin{array}{l}\mathrm{MA}_{\overline{1}} \\
\text { TOT } \\
\text { (cond) }\end{array}$ & QPM & AR1 \\
\hline 1 & 0.39 & 1.54 & 0.16 & 0.04 & 0.30 & -0.53 \\
\hline 2 & 1.78 & 2.57 & 1.52 & 1.41 & 0.38 & -0.80 \\
\hline 3 & 2.81 & $3.27^{* *}$ & 2.44 & 2.19 & 1.44 & -0.94 \\
\hline 4 & 2.84 & $2.93^{* *}$ & 2.13 & 1.91 & 1.65 & -1.69 \\
\hline 5 & 1.17 & 1.06 & 0.41 & 0.89 & 1.12 & $-3.57^{* *}$ \\
\hline 6 & 0.41 & 0.06 & -0.53 & -0.64 & 0.75 & $-4.49^{* *}$ \\
\hline
\end{tabular}

Note: Based on the results of a simple unbiasedness test ${ }^{4}$, asterisks indicate that the null hypothesis of unbiasedness is rejected at the $5 \%$ level.
Tables 8 and 9 present the values of CPI and GDP forecast bias for quarter-over-quarter indicators. Regarding $\mathrm{CPI}$, the hypothesis of unbiasedness is rejected only for some forecast horizons for the MA_P and AR1 models. Also, except for the AR1 forecasts, a positive forecast bias is observed almost within the whole forecast horizon, meaning that the models on average underpredict inflation. As during the period of the forecasting exercise during which the disinflation occurred, lower forecasting values may mean that models are assuming faster convergence to the steady state than happened in real life. Moreover, the forecasts at the horizon of interest are less biased. In the 5th and 6th quarters, the forecast bias of the models is decreasing. For the MA_TOT model, it even becomes slightly negative in the 6th quarter.

Regarding GDP, the conditional forecasts of the BVAR have the smallest bias in absolute terms. However, contrary to other models, the errors of BVAR conditional forecasts have negative sign, meaning overprediction of GDP. Such a difference in the biases between conditional and unconditional forecasts may indicate the importance of conditioning for GDP forecasts.

Taking into consideration that official NBU forecasts are available only on a year-over-year basis, it is not possible to include them into the above comparison. However, if we look at Figure C.8, Appendix C, official NBU forecasts on a yearover-year basis seem to be biased towards under-forecast. There may be several reasons that contribute to this. First, under the inflation-targeting regime, the NBU may have tried to anchor inflation expectations by approaching forecasts to the target, which was lower than the actual inflation. Second, for both conditional BVAR forecasts and QPM forecasts, the observed values of external sector indicators are used. Whereas during the real forecasting process, these values are unknown and the values that are assumed may differ from actual ones.

Finally, I would like to address an issue that has received much attention lately. As the estimation period ends in 2020Q1, the forecasting accuracy of the BVAR during COVID-19 cannot be analyzed. However, the issue of dealing with COVID-19 outliers remains of key interest at the NBU because the developed BVAR model is going to be used for forecasting inflation and GDP in the years to come. There are several papers offering some solutions to the problem, which are applicable to the model I consider.

Table 9. Forecast Bias (GDP)

\begin{tabular}{c|c|c|c|c|c|c}
\hline & \multicolumn{6}{|c}{ GDP } \\
\hline$q$ & MB & MA_P & $\begin{array}{c}\text { MA_ } \\
\text { TOT }\end{array}$ & $\begin{array}{c}\text { MA } \\
\text { TOT } \\
\text { (cond) }\end{array}$ & QPM & AR1 \\
\hline 1 & 0.35 & 0.35 & 0.42 & -0.23 & 0.99 & $1.99^{* *}$ \\
\hline 2 & 0.09 & 0.32 & 0.33 & -0.64 & 0.79 & $2.59^{* *}$ \\
\hline 3 & 0.25 & 0.66 & 0.71 & -0.29 & 0.50 & $2.97^{* *}$ \\
4 & 0.16 & 0.66 & 0.69 & -0.13 & 0.31 & $2.84^{* *}$ \\
\hline 5 & -0.14 & 0.24 & 0.29 & -0.60 & -0.52 & $2.37^{* *}$ \\
6 & -0.34 & 0.11 & 0.03 & -0.22 & -0.75 & $2.08^{* *}$ \\
\hline
\end{tabular}

Note: Based on the results of a simple unbiasedness test, asterisks indicate that the null hypothesis of unbiasedness is rejected at the $5 \%$ level.

\footnotetext{
${ }^{4}$ Unbiasedness test for the forecast error $e_{t+h}$ for forecast horizon $h$ implemented with a t-test in the following regression: $e_{t+h}=y_{t+h}-y_{t+h t}^{f}=\tau_{h}+\varepsilon_{t}$, where the null
} hypothesis is $\tau_{h}=0$ 
Foroni et al. (2020) consider simple methods to improve growth nowcasts and forecasts. Specifically, they combine forecasts across various specifications for the same model or across different models, extend the model specification by adding MA terms, and adjust the forecasts to put them back on track by a specific form of intercept correction etc. They find that among all these methods, adjusting the original forecasts by an amount similar to the forecast errors made during the financial crisis, as well as the following recovery, seems to produce the best results for the U.S. notwithstanding the different source and characteristics of the financial and COVID crises.

Lenza and Primiceri (2020) show how to handle a problem with COVID-19 outliers when estimating VAR models. Their solution consists of explicitly modeling the large change in shock volatility during the pandemic.

Type-1 and Type-2 publication biases, assessing both the extent of selecting only statistically significant estimates for publishing and the extent of selecting the estimates, which are consistent with economic theory. The results of the implemented tests have demonstrated that there is no statistically significant evidence of both types of publication biases in the estimates. The results of meta-regression have shown that the interconnection between interest rates and exchange rates is highly sensitive to a range of macroeconomic factors, especially when we are talking about the level of monetary freedom. Also, the effect was stronger for studies undertaken on post-1990 data.

Although due to data limitations, the inference about the possible effect of interest rate on exchange rate is made based on cross-country evidence rather than on the analysis of Ukrainian data, there is still a high probability that the same kind of relationship might be observed in Ukraine. Although there is no point in discussing the direct estimation of such a monetary policy instrument as the key policy rate on the national currency, the National Bank of Ukraine should take into account such an indirect inference while making its decisions regarding the key policy rate.

\section{CONCLUSIONS}

In this paper, I examined the forecasting performance of a Bayesian Vector Autoregression model with a steady-state prior for Ukrainian economy and compared the accuracy of the forecasts against the forecasts of the QPM model and official NBU forecasts. The RMSE is employed as the measure of forecasting performance. As the forecasting performance for inflation at the monetary policy horizon is of most interest, I focused on the horizon from the fourth to sixth quarters.

The BVAR model was estimated using both data for the Ukrainian economy and foreign indicators. In addition to the benchmark specification, models that include data on commodity prices and terms of trade were included in the alternative specifications to take into account the peculiarities of the Ukrainian economy. The model containing the terms of trade indicator happened to have the most accurate unconditional forecasts of inflation and GDP growth and outperformed the AR1 model at the horizon of interest. For this reason, it was further used to produce conditional forecasts.

The conditional forecasts of the BVAR model were compared to the forecasts of the QPM model. In general, for both inflation and GDP growth, the BVAR model forecasts are competitive with the QPM forecasts.

As the NBU forecasts are only available on a year-overyear basis, the conditional BVAR forecasts were transformed from annualized quarter-over-quarter indicators into yearover-year indicators to compare the forecast accuracy. The BVAR forecasts of inflation outperform the official NBU forecasts at the horizon of interest, whereas the opposite is true for the forecasts of GDP growth. In the short run, NBU forecasts dominate probably because the NBU is considering a broader information set during the forecasting process and different types of models specifically designed for short-run forecasting. 


\section{REFERENCES}

Beechey, M., Österholm, P. (2010). Forecasting inflation in an inflation-targeting regime: A role for informative steadystate priors. International Journal of Forecasting, 26(2), 248-264. https://doi.org/10.1016/j.ijforecast.2009.10.006

Brazdik, F., Franta, M. (2017). A BVAR model for forecasting of Czech inflation. Working Papers 2017/7. Praha: Czech National Bank. Retrieved from https://www.cnb.cz/ export/sites/cnb/en/economic-research/.galleries/research_ publications/cnb_wp/cnbwp_2017_07.pdf

Carriero, A., Kapetanios, G., Marcellino, M. (2009). Forecasting exchange rates with a large Bayesian VAR. International Journal of Forecasting, 25(2), 400-417. https://doi.org/10.1016/j.ijforecast.2009.01.007

Chan, J., Jacobi, L., Zhu, D. (2019). Efficient selection of hyperparameters in large Bayesian VARs using automatic differentiation. CAMA Working Papers, 46/2019. The Australian National University. Retrieved from https://crawford.anu.edu. au/sites/default/files/publication/cama_crawford_anu_edu_ au/2019-06/46_2019_chan_jacobi_zhu.pdf

Clark, T. E. (2011). Real-time density forecasts from Bayesian vector autoregressions with stochastic volatility. Journal of Business and Economics Statistics, 29(3), 327-341. https://doi.org/10.1198/jbes.2010.09248

Del Negro, M., Schorfheide, F. (2004). Priors from general equilibrium models for VARs. International Economic Review, 45, 643-673. https://doi.org/10.1111/j.14682354.2004.00139.x

Dieppe, A., Legrand, R., van Roye, B. (2016). The BEAR toolbox. Working Paper Series, 1934. European Central Bank. Retrieved from https://www.ecb.europa.eu/pub/pdf/ scpwps/ecbwp1934.en.pdf

Foroni, C., Marcellino, M., Stevanović, D. (2020). Forecasting the Covid-19 recession and recovery: lessons from the financial crisis. Working Paper Series, 2468. European Central Bank. Retrieved from https://www.ecb. europa.eu/pub/pdf/scpwps/ecb.wp2468 068eec9e3e. en.pdf

Giannone, D., Lenza, M., Primiceri, G., (2012). Prior selection for vector autoregressions. Working Paper Series, 1494. European Central Bank. Retrieved from https://www. ecb.europa.eu/pub/pdf/scpwps/ecbwp1494.pdf
Grui, A., Vdovychenko, A. (2019). Quarterly projection model for Ukraine. NBU Working Papers, 3/2019. Kyiv: National Bank of Ukraine. Retrieved from https://bank.gov.ua/ admin_uploads/article/WP_2019-03_Grui_Vdovychenko_ en.pdf

Gustafsson, O., Villani, M., Stockhammar, P. (2020). Bayesian optimization of hyperparameters when the marginal likelihood is estimated by MCMC. Retrieved from https://arxiv.org/pdf/2004.10092.pdf

Iversen, J., Laseen, S., Lundvall, H., Söderström. U. (2016). Real-time forecasting for monetary policy analysis: The case of Sveriges Riksbank. CEPR Discussion Papers, 11203. Retrieved from http://archive.riksbank.se/Documents/ Rapporter/Working_papers/2016/rap_wp318_160323.pdf

Jarocinski, M. (2010). Conditional forecasts and uncertainty about forecast revisions in vector autoregressions. Economics Letters, 108(3), 257-259. https://doi.org/10.1016/j.econlet.2010.05.022

Krüger, F., Clark, T. E., Ravazzolo, F. (2017). Using entropic tilting to combine BVAR forecasts with external nowcasts. Journal of Business \& Economic Statistics, 35(3), 470-485. https://doi.org/10.1080/07350015.2015.1087856

Lenza, M., Primiceri, G. (2020). How to estimate a VAR after March 2020. Working Paper Series, 2461. European Central Bank. Retrieved from https://www.ecb.europa.eu/ pub/pdf/scpwps/ecb.wp2461 fe732949ee.en.pdf

Robertson, J. C., Tallman, E. W., Whiteman, C. H. (2005). Forecasting using relative entropy. Journal of Money, Credit and Banking, 37(3), 383-401. https://doi.org/10.1353/ mcb.2005.0034

Schorfheide, F., Song, D. (2015). Real-time forecasting with a mixed-frequency VAR. Journal of Business and Economic Statistics, 33(3), 366-380. https://doi.org/10.1080/ 07350015.2014.954707

Villani, M. (2009). Steady-state priors for vector autoregressions. Journal of Applied Econometrics, 24(4), 630-650. https://doi.org/10.1002/jae.1065

Waggoner, D. F., Zha, T., (1999). Conditional forecasts in dynamic multivariate models. The Review of Economics and Statistics, 81(4), 639-651. https://doi. org/10.1162/003465399558508 


\section{APPENDIX A}

\section{Gibbs sampling algorithm for BVAR with steady-state prior}

1. Define the number of iterations It of the algorithm, and the burn-in sample $u$.

2. Define initial values $\beta_{0}, B_{0}, \Sigma_{0}$ for the algorithm. Obtain the initial value for $U$ from $\beta_{0}$,

3. At iteration $n$, draw $\psi_{(n)}$, conditional on $\beta_{(n-1)}$, and $\Sigma_{(n-1)}$. Draw $\psi_{(n)}$, from a multivariate normal:

$\pi\left(\psi \mid \beta_{(n-1)} \Sigma_{(n-1)}, y\right) \sim \mathrm{N}(\bar{\psi}, \bar{\Lambda})$

$\bar{\Lambda}=\left[\Lambda_{0}^{-1}+U^{\prime}\left(Z^{\prime} Z \otimes \Sigma_{(n-1)}^{-1}\right) U\right]^{-1}, \bar{\psi}=\bar{\Lambda}\left[\Lambda_{0}^{-1} \psi_{0}+U^{\prime} \operatorname{vec}\left(\Sigma_{(n-1)}^{-1}\left(Y-X B_{(n-1)}^{\prime}\right) Z\right]\right.$

Reshape $\psi_{(n)}$, to obtain $F_{(n)}$.

4. Use $F_{(n)}$ to obtain $\hat{Y}, \hat{X}$ and $\hat{y}$.

5. Draw the value $\Sigma_{(n)}$, conditional on $B_{(n-1)}$ and $\psi_{(n)}$. Draw $\Sigma_{(n)}$, from an inverse Wishart distribution with scale matrix $\tilde{S}$ and degrees of freedom $T$ :

$\pi\left(\Sigma_{(n)} \mid B_{(n-1)} \psi_{(n)}, y\right) \sim I W(\tilde{S}, T)$

$\tilde{S}=\left(\hat{Y}-\hat{X} B_{(n-1)}\right)^{\prime}\left(\hat{Y}-\hat{X} B_{(n-1)}\right)$

6. Finally, draw $\beta_{(n)}$ conditional on $\Sigma_{(n)}$ and $\psi_{(n)}$, and reshape into $B_{(n)}$. Draw $\beta_{(n)}$, from a multivariate normal distribution with $\bar{\beta}$ mean and covariance matrix $\bar{\Omega}$ :

$\pi\left(\beta_{(n)} \mid \Sigma_{(n)} \psi_{(n)}, y\right) \sim \mathrm{N}(\bar{\beta}, \bar{\Omega})$

$\bar{\Omega}=\left[\Omega_{0}{ }^{-1}+\Sigma_{(n)}^{-1} \otimes \hat{X}^{\prime} \hat{X}\right]^{-1}, \bar{\beta}=\left[\Omega_{0}^{-1} \beta_{0}+\left(\Sigma_{(n)}^{-1} \otimes \hat{X}^{\prime}\right) \hat{y}\right]$

Update $U$ from $B_{(n)}$.

7. Repeat until $I t$ iterations are realized, then discard the first $B u$ iterations.

Note that $\hat{y}_{t}$ is a demeaned data vector $\hat{y}_{t}=y_{t}-F x_{t}$ and $A(L) \hat{y}_{t}=\varepsilon_{t}$ is a VAR in standard form conditional on $F$.

$\hat{X}$ and $\hat{Y}$ are defined as $Y$ and $X$ in accordance with (5) using $\hat{y}_{t}$ rather than $\hat{y}_{t}$. 


\section{APPENDIX B. TABLES}

Table B.1. Data Used for the Research

\begin{tabular}{|c|c|c|c|}
\hline Series & Name & Definition & Source \\
\hline Foreign output & $\begin{array}{l}\text { gdpw1 } \\
\text { gdpw2 } \\
\text { gdpw3 }\end{array}$ & $\begin{array}{l}\text { Trade-weighted index of real GDP of } \\
\text { major trading partners ( } 3,5 \text { and } 40^{*} \\
\text { countries) }\end{array}$ & $\begin{array}{l}\text { NBU staff calculations, based on the } \\
\text { data from national statistics committees } \\
\text { (NSC) }\end{array}$ \\
\hline Foreign output & $\begin{array}{l}\text { cpineerw1 } \\
\text { cpineerw2 } \\
\text { cpineerw3 } \\
\text { ppineerw1 } \\
\text { ppineerw2 }\end{array}$ & $\begin{array}{l}\text { Trade-weighted index of CPI of major } \\
\text { trading partners (3*, } 5 \text { and } 40 \text { countries) } \\
\text { Trade-weighted index of PPI of major } \\
\text { trading partners ( } 3 \text { and } 5 \text { countries) }\end{array}$ & $\begin{array}{l}\text { NBU staff calculations, based on the } \\
\text { data from NSC } \\
\begin{array}{l}\text { NBU staff calculations, based on the } \\
\text { data from NSC }\end{array}\end{array}$ \\
\hline $\begin{array}{l}\text { Commodity prices on } \\
\text { foreign markets }\end{array}$ & $\begin{array}{l}\text { wbnonen } \\
\text { wben } \\
\text { fao } \\
\text { psteel } \\
\text { pgrains }\end{array}$ & $\begin{array}{l}\text { Non-energy commodities price index } \\
\text { Energy commodities price index } \\
\text { FAO price index } \\
\text { Export price of steel } \\
\text { Export price of grains }\end{array}$ & $\begin{array}{l}\text { World bank commodity prices, FAO } \\
\text { database, export and import prices from } \\
\text { SSSU }\end{array}$ \\
\hline Foreign interest rate & $\begin{array}{l}\text { iw1 } \\
\text { iw2 }\end{array}$ & $\begin{array}{l}\text { 1-month LIBOR Rate* } \\
\text { overnight LIBOR Rate }\end{array}$ & Thomson Reuters Datastream \\
\hline Domestic output & gdpua & Ukrainian GDP at constant prices* & State Statistics Service of Ukraine (SSSU) \\
\hline Domestic price level & cpiua & $\mathrm{CPI}^{*}$ & SSSU \\
\hline $\begin{array}{l}\text { Domestic interest } \\
\text { rate }\end{array}$ & iua & NBU policy rate* & NBU \\
\hline $\begin{array}{l}\text { Nominal effective ex- } \\
\text { change rate (+ means } \\
\text { an appreciation) }\end{array}$ & $\begin{array}{l}\text { neer1 } \\
\text { neer2 } \\
\text { neer3 }\end{array}$ & $\begin{array}{l}\text { Real effective exchange rate deflated by } \\
\text { CPI }\left(3^{*}, 5 \text { and } 40 \text { countries) }\right.\end{array}$ & $\begin{array}{l}\text { NBU staff calculations, based on the } \\
\text { data from national statistics committees, } \\
\text { Bloomberg, NBU data }\end{array}$ \\
\hline $\begin{array}{l}\text { Real effective ex- } \\
\text { change rate (+means } \\
\text { an appreciation) }\end{array}$ & $\begin{array}{l}\text { reercpiw1 } \\
\text { reercpiw2 } \\
\text { reercpiw3 } \\
\text { reerppiw1 } \\
\text { reerppiw2 }\end{array}$ & $\begin{array}{l}\text { Real effective exchange rate deflated } \\
\text { by CPI ( } 3 \text { and } 5 \text { countries) (3,5 and } 40^{*} \\
\text { countries) } \\
\text { Real effective exchange rate deflated by } \\
\text { PPI ( } 3 \text { and } 5 \text { countries) }\end{array}$ & $\begin{array}{l}\text { NBU staff calculations, based on the } \\
\text { data from national statistics committees, } \\
\text { Bloomberg, NBU data }\end{array}$ \\
\hline Terms of trade & $\begin{array}{l}\text { totw1 } \\
\text { totw2 }\end{array}$ & $\begin{array}{l}\text { Commodity terms of trade, based on IMF } \\
\text { methodology } \\
\text { Ratio between the index of export prices } \\
\text { for grains and metals and the index of } \\
\text { import prices for oil and gas* }\end{array}$ & $\begin{array}{l}\text { NBU staff calculations, based on the } \\
\text { SSSU data }\end{array}$ \\
\hline Wage & $\begin{array}{l}\text { nwage } \\
\text { rwage }\end{array}$ & $\begin{array}{l}\text { Average nominal wage } \\
\text { Average real wage* }\end{array}$ & SSSU \\
\hline Monetary aggregate & $\mathrm{m} 2$ & M2 & NBU \\
\hline
\end{tabular}

Note: the time series entering QPM model marked with asterisk. 
Table B.2. Lag Length Criteria

\begin{tabular}{l|c|c|c|c|c|}
\hline & LR & FPE & AIC & SC & HQ \\
\hline MB & 3 & 2 & 5 & 1 & 1 \\
MA_P & 2 & 4 & 5 & 1 & 1 \\
MA_TOT & 4 & 2 & 5 & 1 & 1 \\
\hline
\end{tabular}

Note: numbers in the Table 1 indicate lag order selected by the criterion:

LR: sequential modified LR test statistic (each test at $5 \%$ level)

FPE: Final prediction error

AIC: Akaike information criterion

SC: Schwarz information criterion

HQ: Hannan-Quinn information criterion

Table B.3. Lag Length Criteria

\begin{tabular}{|c|c|c|c|}
\hline & Min value & Max value & Step size \\
\hline Autoregressive coefficient & 0.2 & 1.0 & 0.1 \\
\hline Overall tightness $\left(\lambda_{1}\right)$ & 0.05 & 0.20 & 0.01 \\
\hline Cross-variable weighting $\left(\lambda_{2}\right)$ & 0.1 & 1.0 & 0.1 \\
\hline Lag decay $\left(\lambda_{3}\right)$ & 1.0 & 2.0 & 0.2 \\
\hline
\end{tabular}

Table B.4. Steady State prior Distributions (Villani)

\begin{tabular}{l|c|c|c|c|c|c|c|c}
\hline & \multicolumn{3}{|c|}{ Regime 1: 1980q1 1992q4 } & \multicolumn{4}{c}{ Regime 2: 1993q1 2005q4 } \\
\hline & Mean & Var & $95 \%$ & Interval & Mean & Var & $95 \%$ & Interval \\
\hline GDPw & 2.5 & 0.8 & 1.0 & 4.0 & 2.5 & 0.3 & 2.0 & 3.0 \\
CPIw & 4.0 & 0.5 & 3.0 & 5.0 & 2.0 & 0.3 & 1.5 & 2.5 \\
irw & 7.0 & 0.5 & 6.0 & 8.0 & 5.0 & 0.3 & 4.5 & 5.5 \\
GDP & 2.3 & 0.6 & 1.0 & 3.5 & 2.3 & 0.1 & 2.0 & 2.5 \\
CPI & 7.0 & 0.5 & 6.0 & 8.0 & 2.0 & 0.2 & 1.7 & 2.3 \\
ir & 8.5 & 0.8 & 7.0 & 10.0 & 4.3 & 0.1 & 4.0 & 4.5 \\
REER & 3.9 & 0.3 & 3.4 & 4.5 & 3.9 & 0.0 & 3.9 & 4.0 \\
\hline
\end{tabular}

Table B.5. Steady State prior Distributions (Brazdik and Franta)

\begin{tabular}{l|c|c|c|c|c|c|c|c|c|c|c|c}
\hline & \multicolumn{3}{|c|}{ Regime 1: 2008q3 2010q1 } & \multicolumn{3}{c}{ Regime 1: 2010q2 2013q3 } & \multicolumn{4}{c}{ Regime 1: 2013q4 2016q4 } \\
\hline & Mean & Var & $95 \%$ & Interval & Mean & Var & $95 \%$ & Interval & Mean & Var & $95 \%$ & Interval \\
\hline GDPw & 9.4 & 3.1 & 3.4 & 15.4 & 8.9 & 2.0 & 4.9 & 12.9 & 7.2 & 1.0 & 5.2 & 9.2 \\
CPIw & 2.0 & 1.5 & -1.0 & 5.0 & 2.0 & 1.0 & 0.0 & 4.0 & 2.0 & 0.5 & 1.0 & 3.0 \\
Euribor 3m & 4.0 & 1.5 & 1.0 & 7.0 & 4.0 & 1.0 & 2.0 & 6.0 & 3.5 & 0.5 & 2.5 & 4.5 \\
GDP & 5.0 & 1.5 & 2.0 & 8.0 & 4.0 & 1.0 & 2.0 & 6.0 & 3.0 & 0.5 & 2.0 & 4.0 \\
CPI & 3.0 & 1.0 & 1.0 & 5.0 & 2.0 & 0.5 & 1.0 & 3.0 & 2.0 & 0.3 & 1.5 & 2.5 \\
Pribor 3m & 3.0 & 4.1 & -0.5 & 15.4 & 3.0 & 1.3 & 0.5 & 5.5 & 3.0 & 0.8 & 1.5 & 4.5 \\
CZK/EuRO & -2.4 & 3.1 & -8.4 & 3.6 & -2.4 & 2.0 & -6.4 & 1.6 & -1.5 & 1.0 & -3.5 & 0.5 \\
\hline
\end{tabular}


APPENDIX C. FIGURES
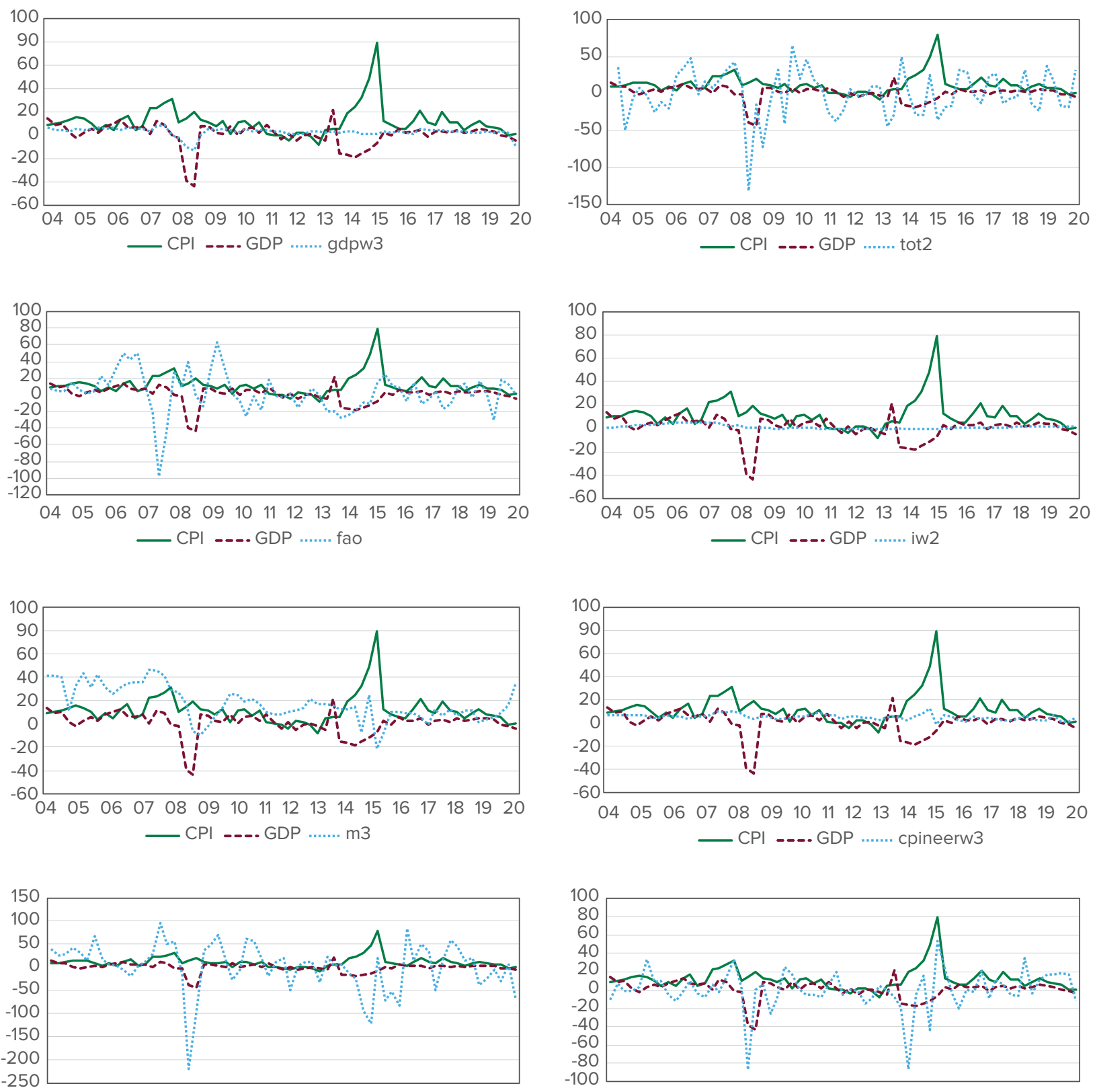

$\begin{array}{lllllllllllllllll}04 & 05 & 06 & 07 & 08 & 09 & 10 & 11 & 12 & 13 & 14 & 15 & 16 & 17 & 18 & 19 & 20\end{array}$ _ CPI _... GDP ....... wben

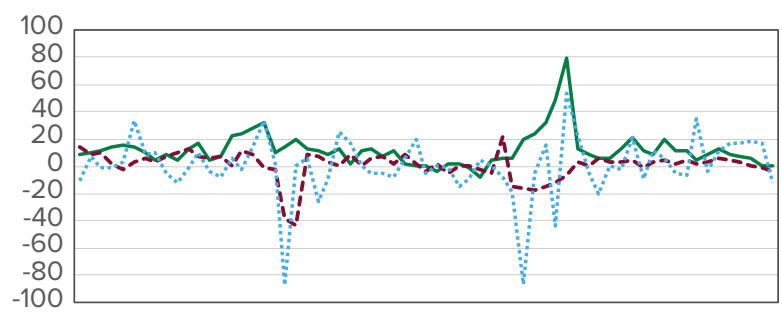

$\begin{array}{lllllllllllllllll}04 & 05 & 06 & 07 & 08 & 09 & 10 & 11 & 12 & 13 & 14 & 15 & 16 & 17 & 18 & 19 & 20\end{array}$ — CPI _... GDP ........ reercpiw3
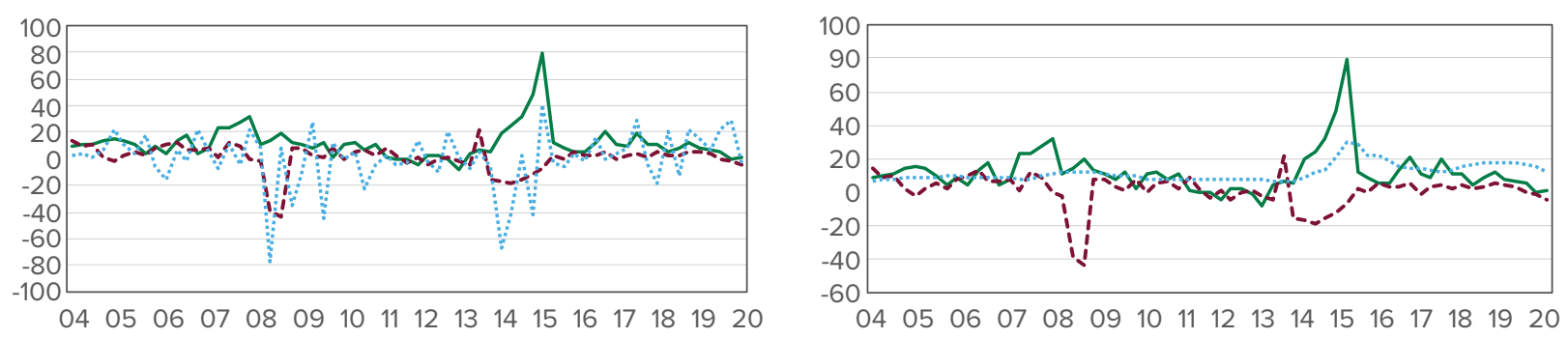
—CPI _.... GDP ....... totw3

—CPI -... GDP ....... iua

Figure C.1. CPI, GDP and Series Chosen for Models, yoy, in logs 

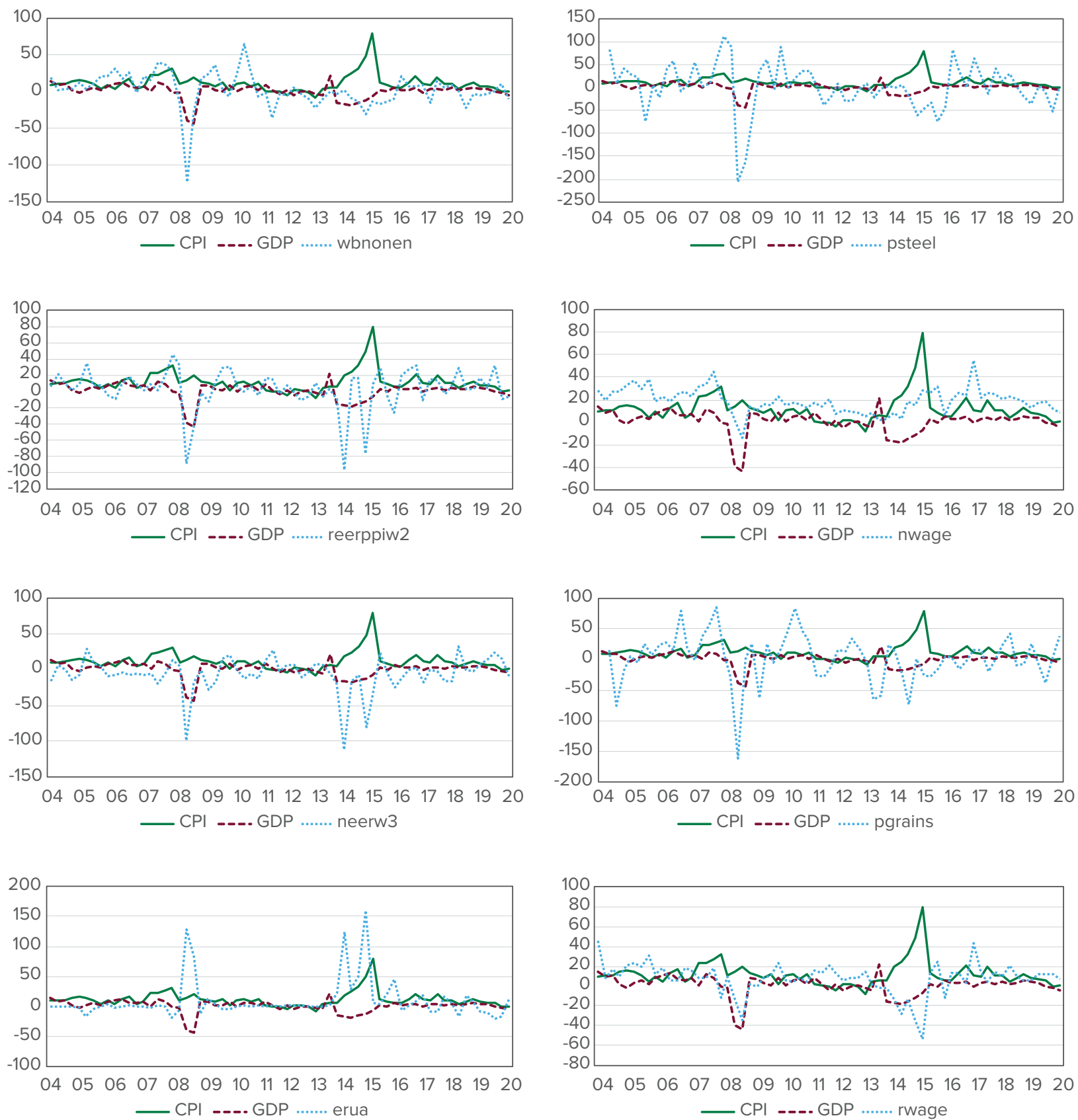

Figure C.1 (continued). CPI, GDP and Series Chosen for Models, yoy, in logs 

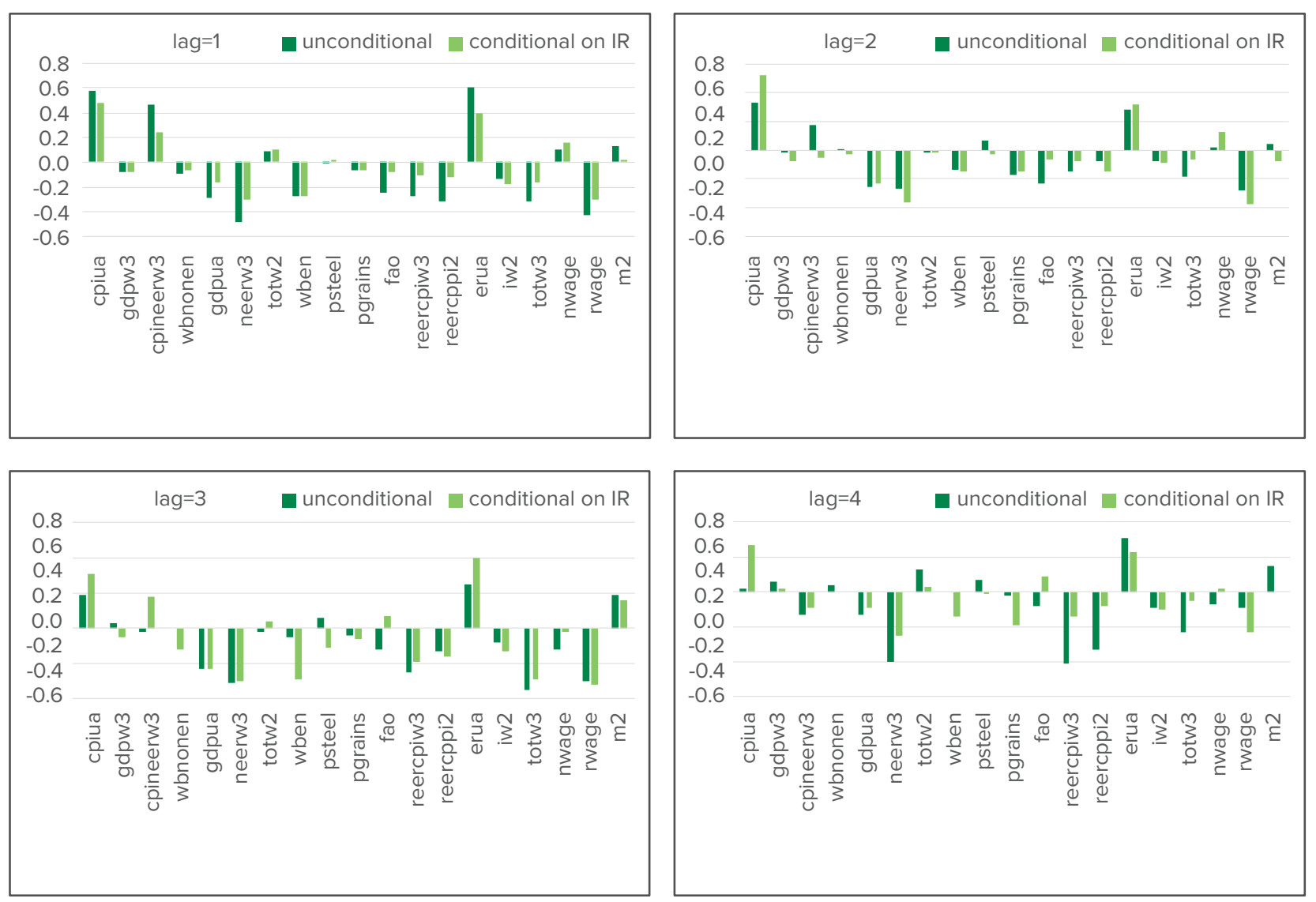

Figure C.2. Conditional and Unconditional Correlations 

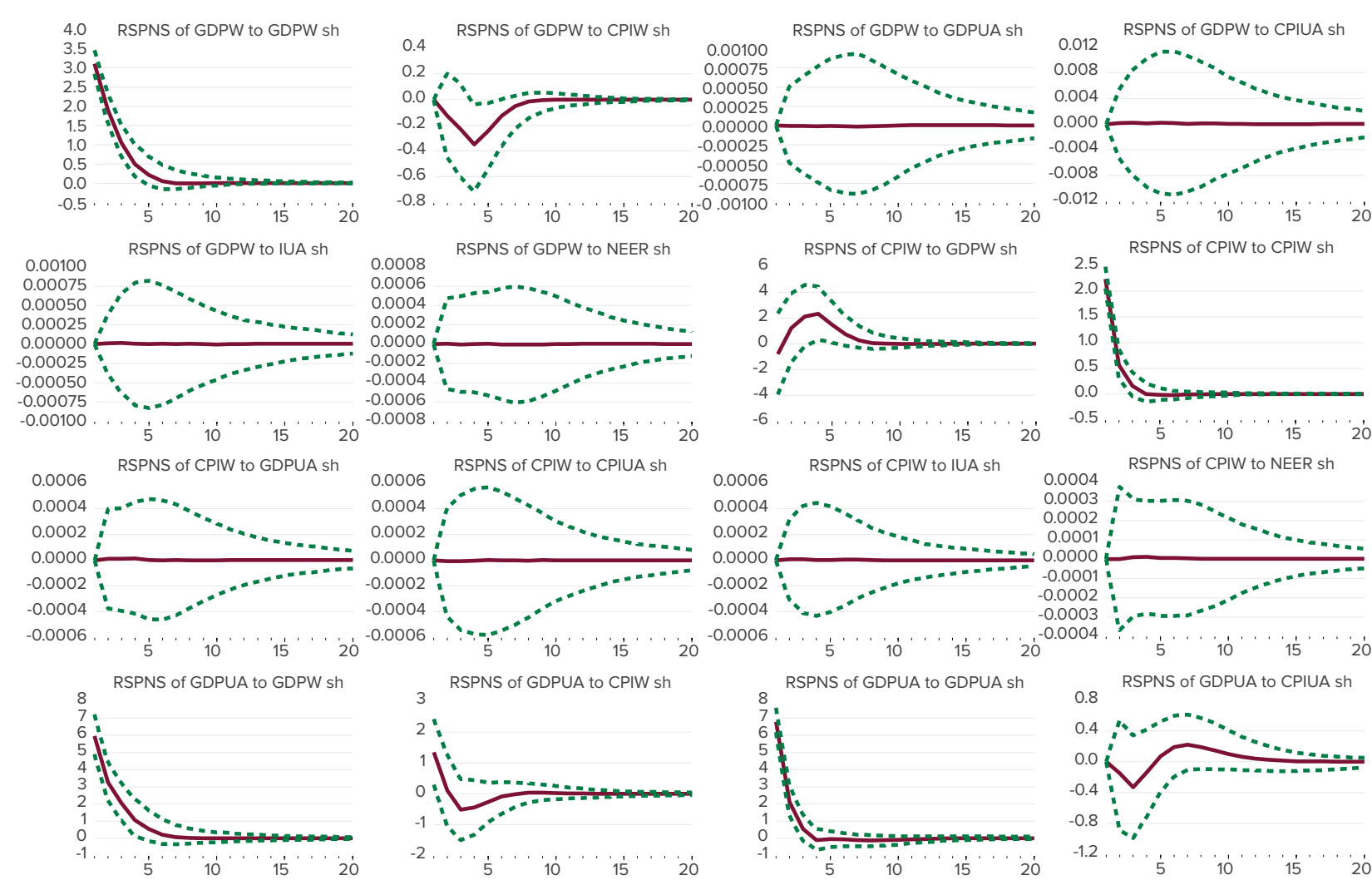

RSPNS of CPIW to NEER Sh
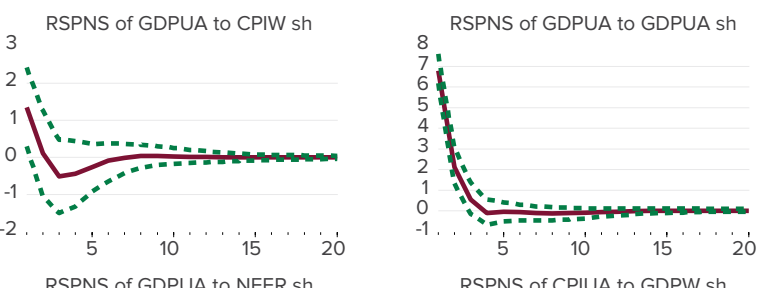

RSPNS of GDPUA to IUA sh
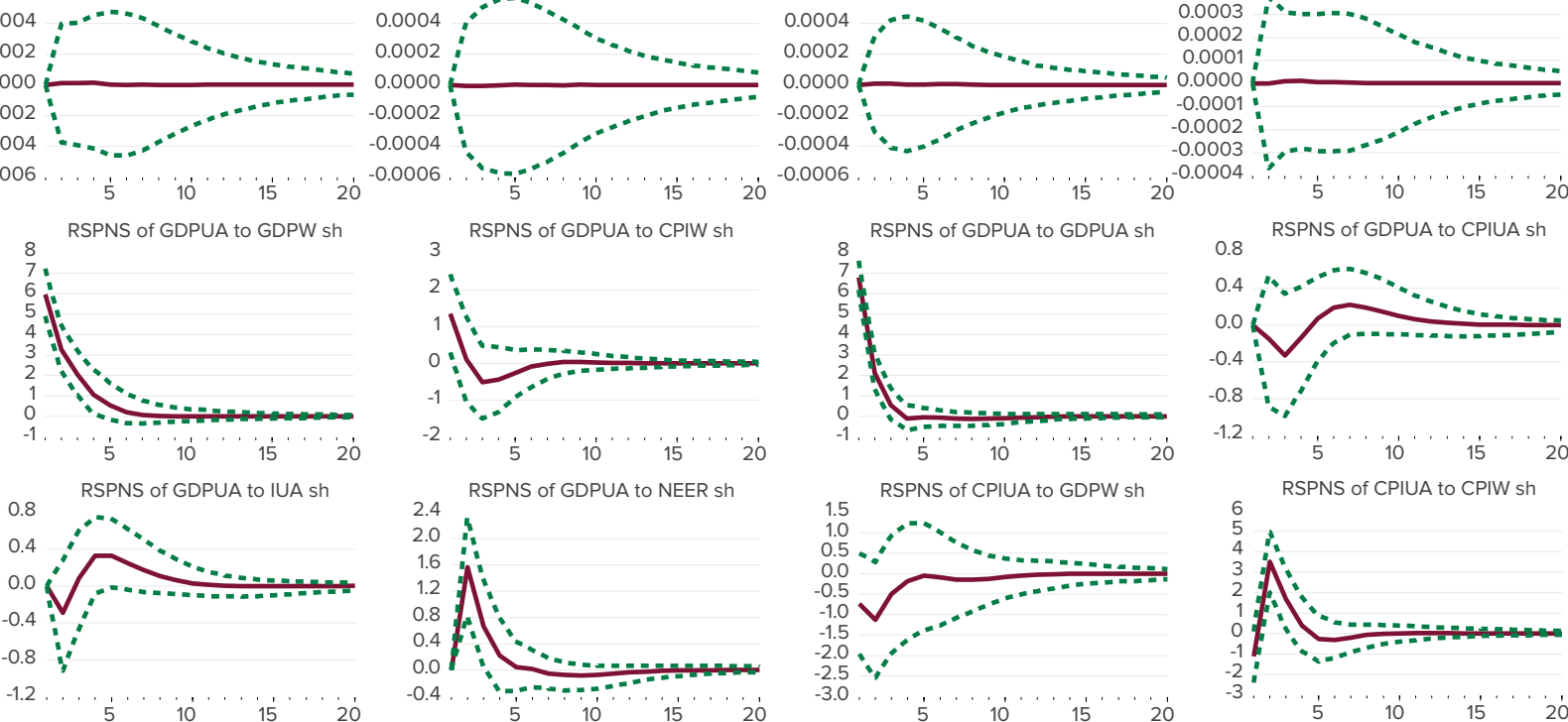

RSPNS of CPIUA to CPIUA sh
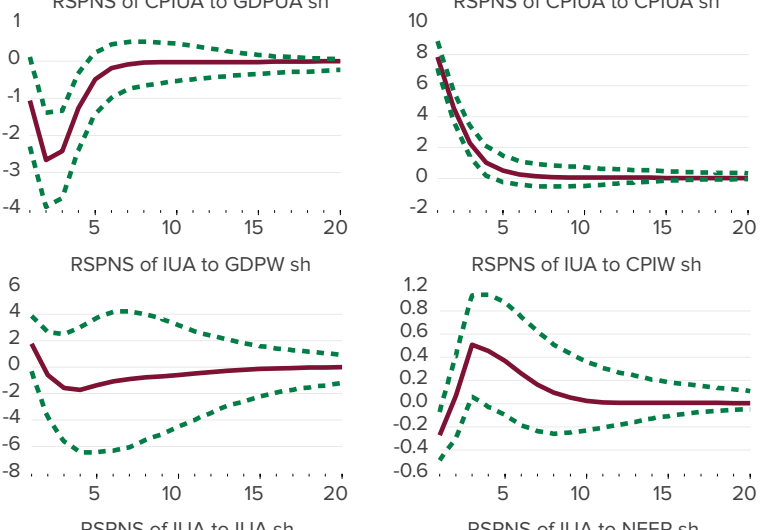

RSPNS of CPIUA to IUA sh
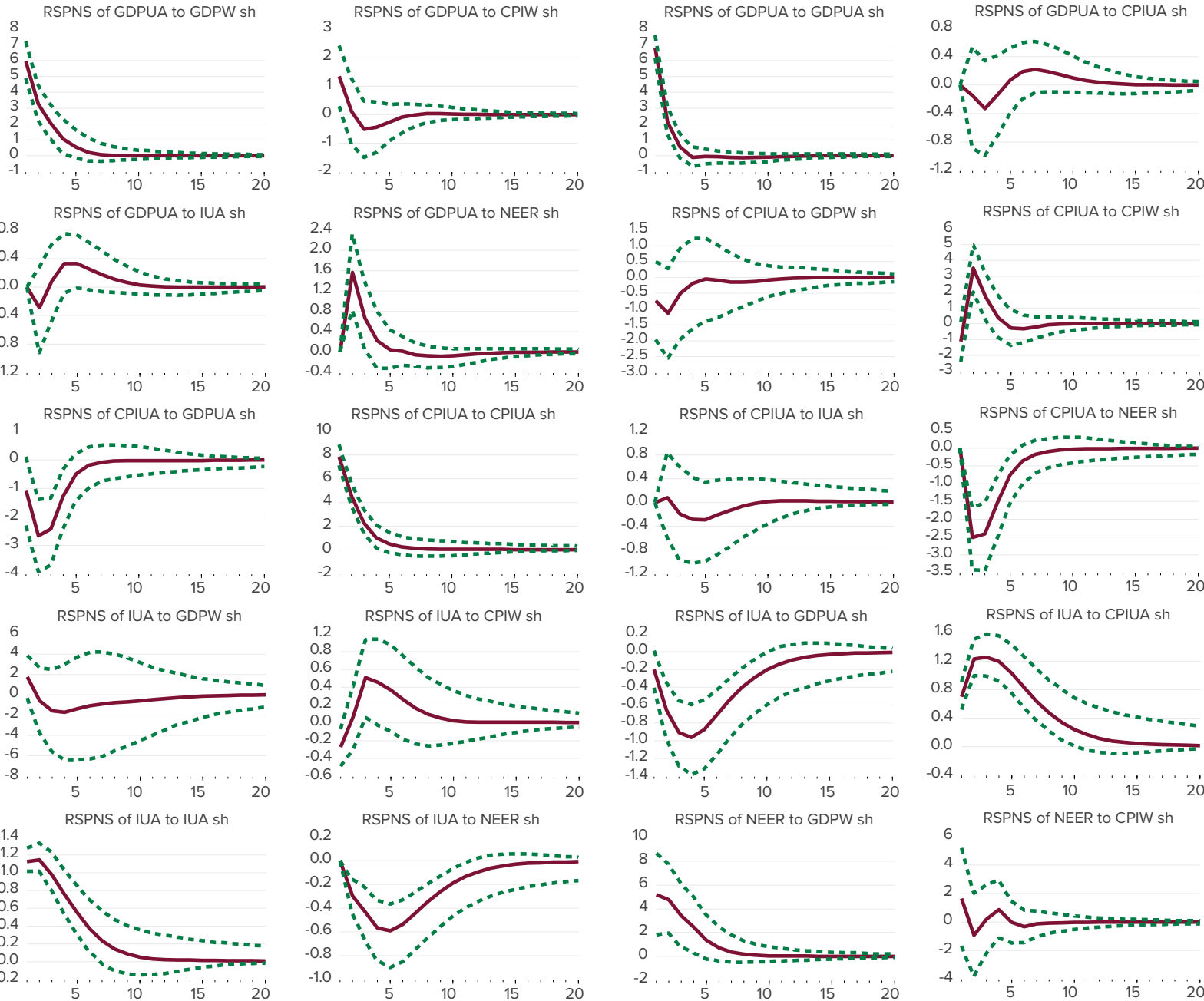

RSPNS of IUA to NEER Sh
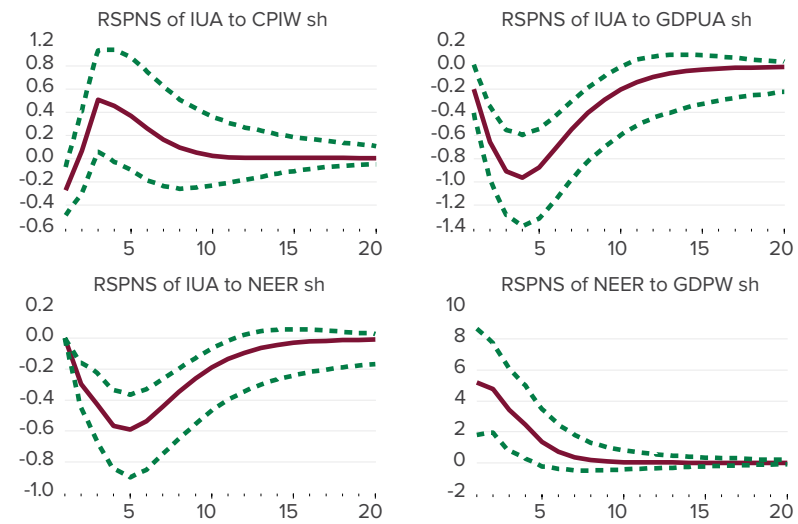

RSPNS of IUA to CPIUA sh

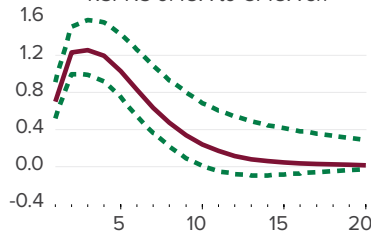

RSPNS of NEER to GDPW sh

RSPNS of NEER to CPIW sh

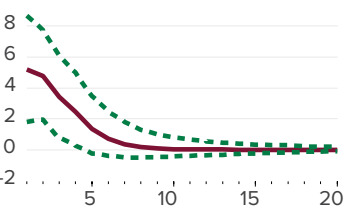

$4:$

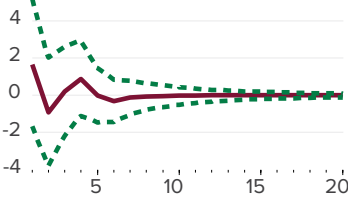

RSPNS of NEER to CPIUA sh

RSPNS of NEER to IUA sh
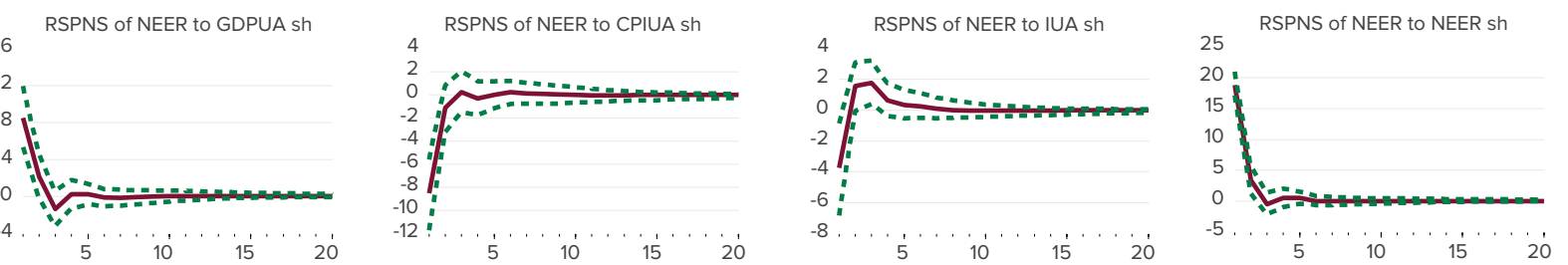

Figure C.3. Impulse Response Functions, MB Model 

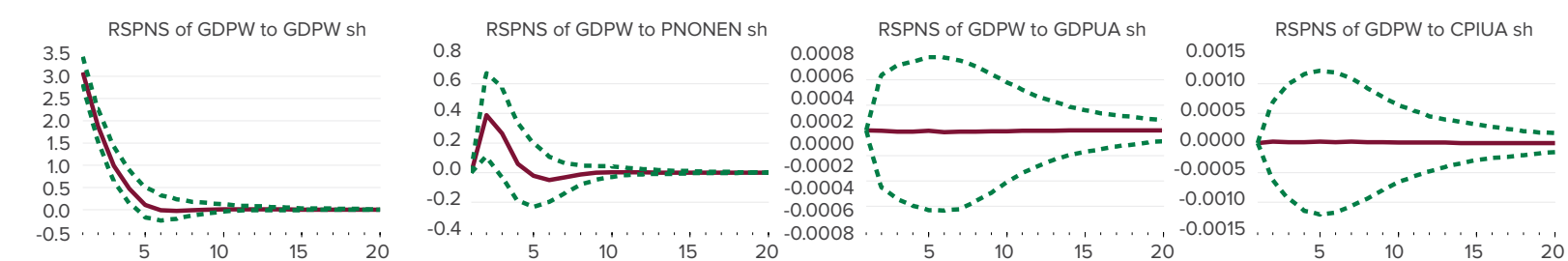

RSPNS of GDPW to IUA sh

RSPNS of GDPW to NEER sh

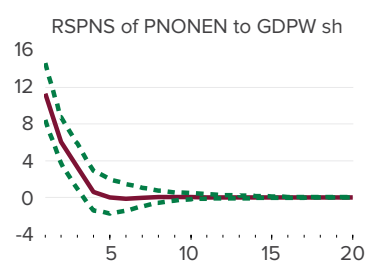

RSPNS of PNONEN to PNONEN sh

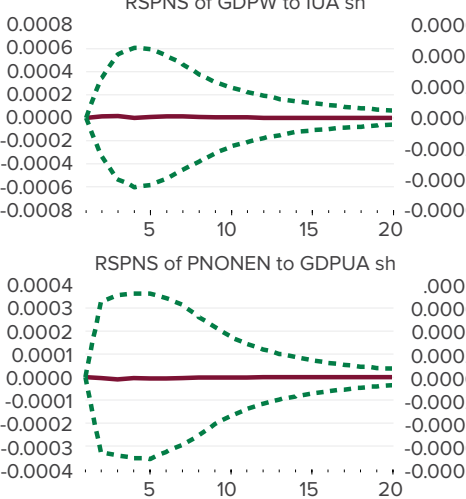

RSPNS of GDPUA to GDPW sh

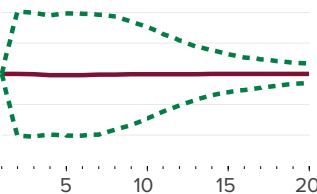

RSPNS Of PNONEN to CPIUA sh

RSPNS Of PNONEN to IUA sh
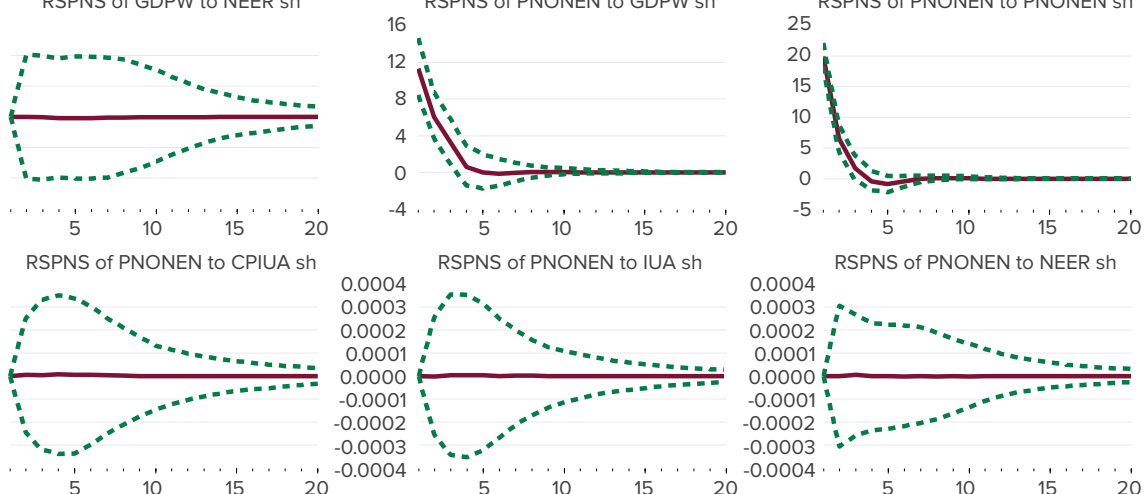

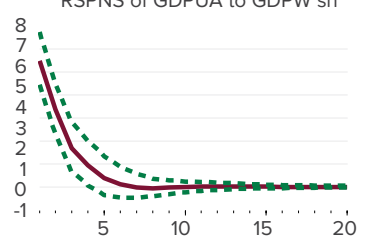

RSPNS of GDPUA to IUA sh

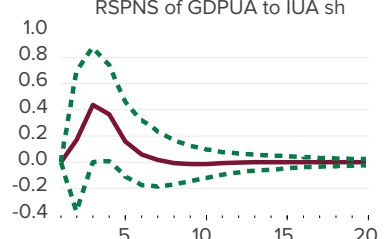

RSPNS of CPIUA to GDPUA sh

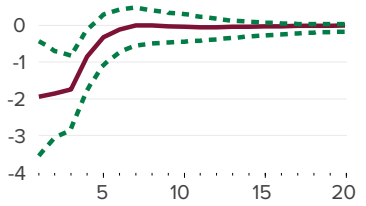

RSPNS of IUA to GDPW sh
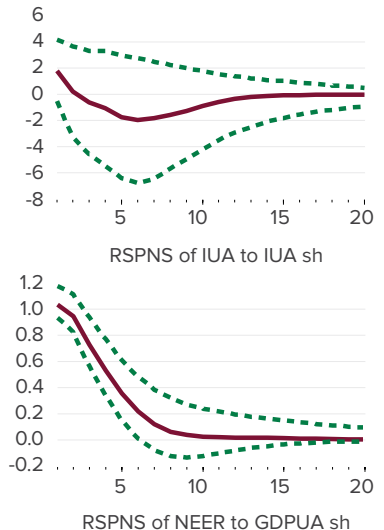
16

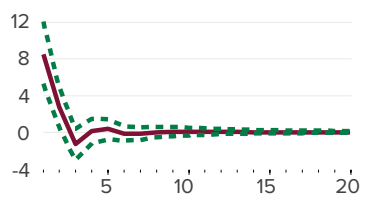

RSPNS of GDPUA to PNONEN sh

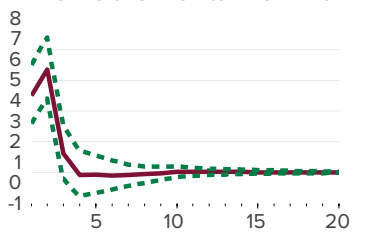

RSPNS of GDPUA to NEER sh

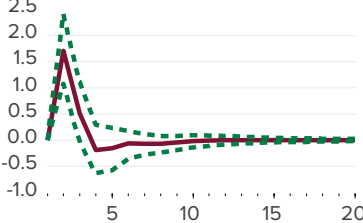

RSPNS of CPIUA to CPIUA sh

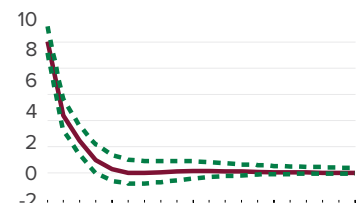

' 5 ' ' ' ' 1' ' ' ' ' ' 15 ' ' ' ' 20 RSPNS of IUA to PNONEN sh
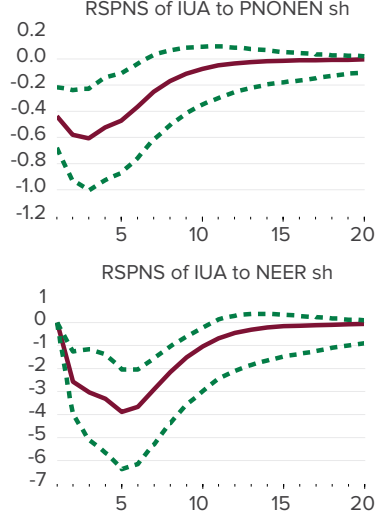

RSPNS of NEER to CPIUA sh

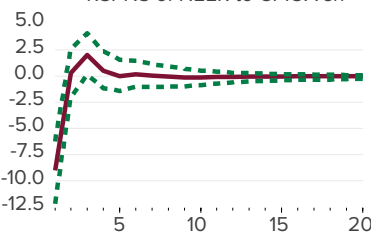

RSPNS of GDPUA to GDPUA sh
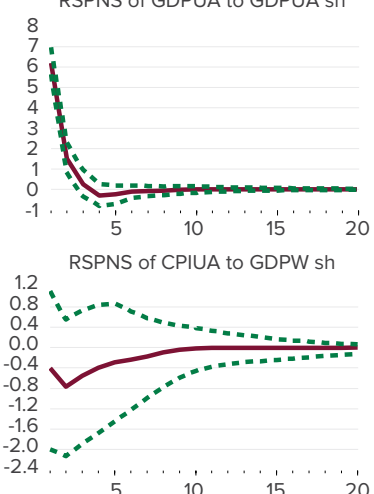

RSPNS of CPIUA to IUA sh

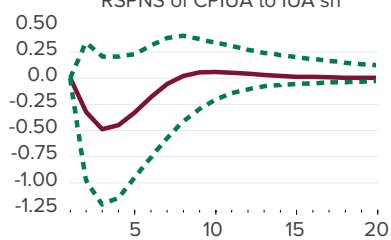

RSPNS of IUA to GDPUA sh

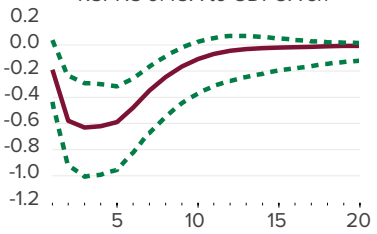

RSPNS of NEER to GDPW sh

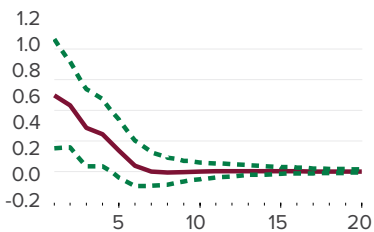

RSPNS of NEER to IUA sh

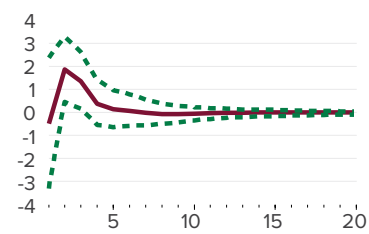

RSPNS Of GDPUA TO CPIUA
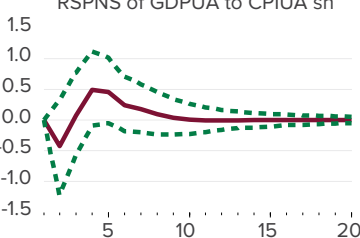
RSPNS of CPIUA to PNONEN Sh 3

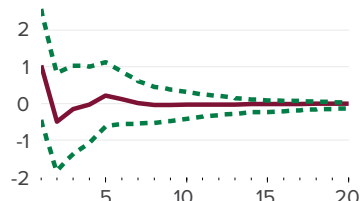

RSPNS of CPIUA to NEER sh

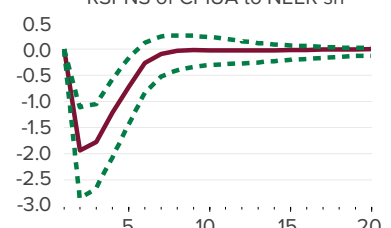

RSPNS of IUA to CPIUA sh

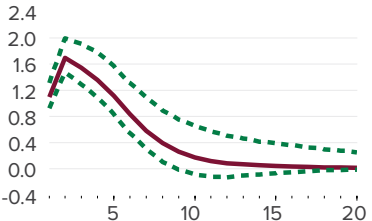

RSPNS of NEER to PNONEN Sh

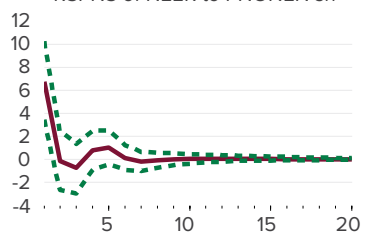

RSPNS of NEER to NEER Sh

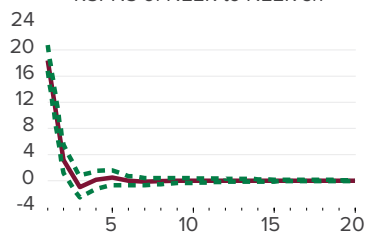

Figure C.4. Impulse Response Functions, MA_P Model 


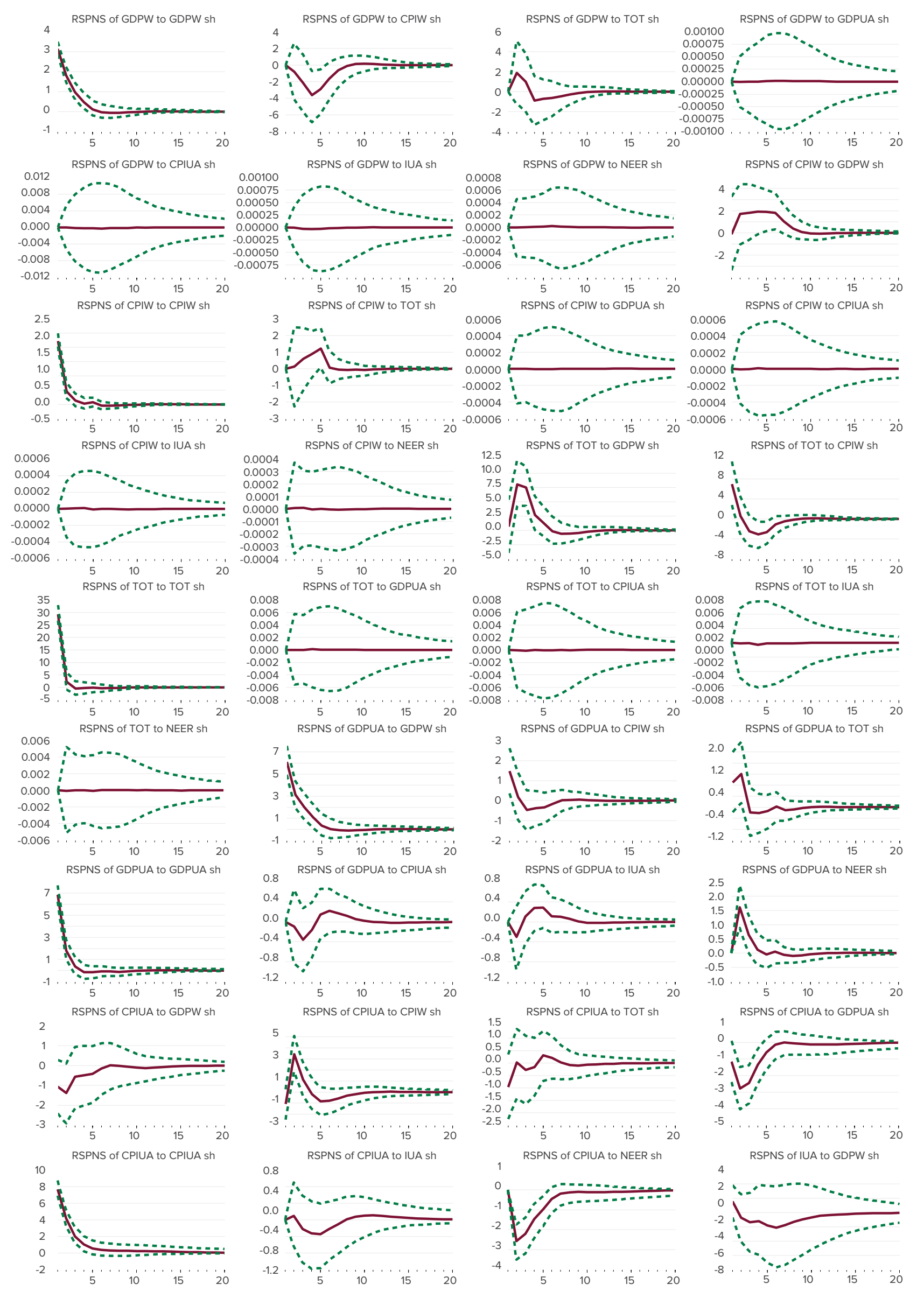

Figure C.5. Impulse Response Functions, MA_TOT Model 

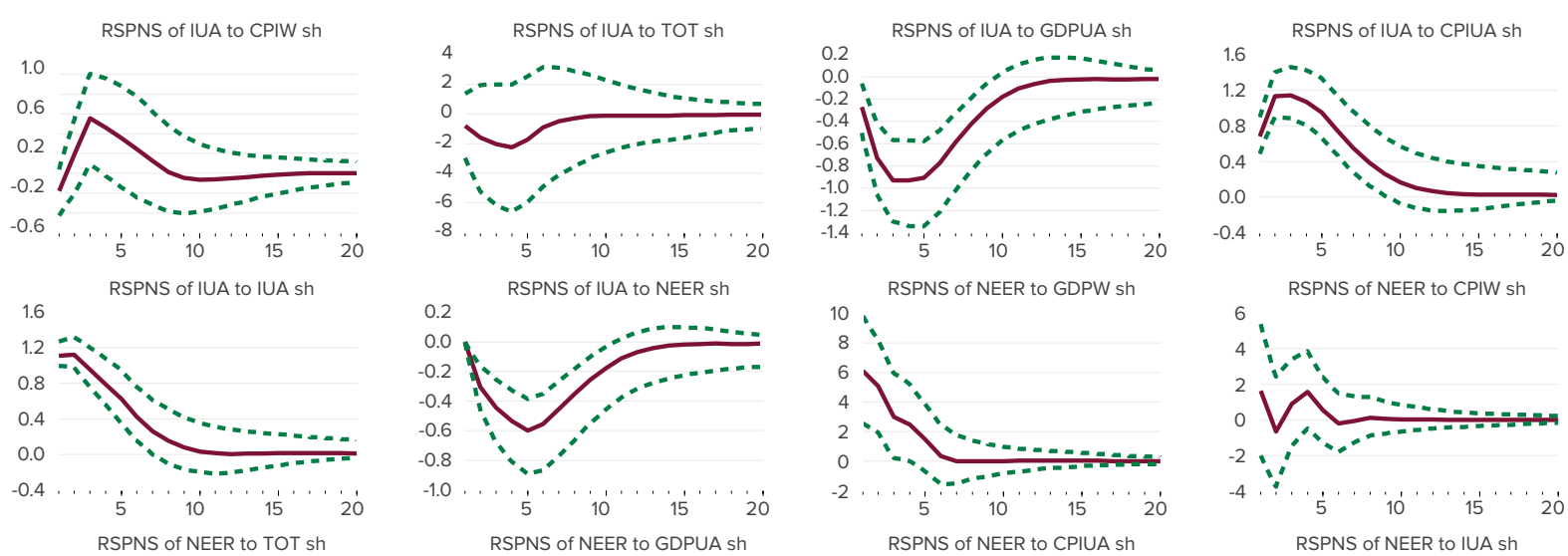

RSPNS of NEER to CPIW sh
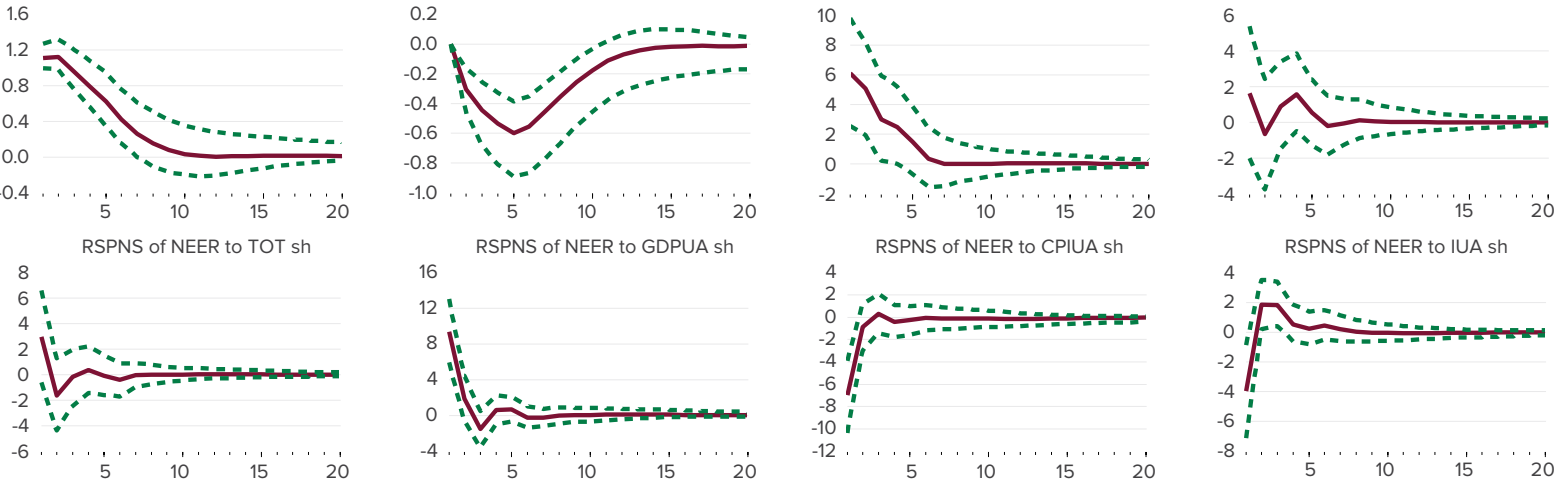
RSPNS of NEER to NEER sh

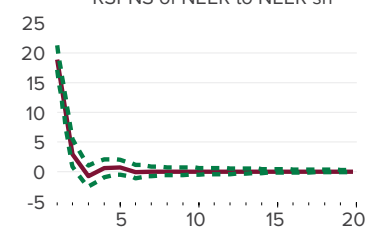

Figure C.5 (continued). Impulse Response Functions, MA_TOT Model 
a) AR1
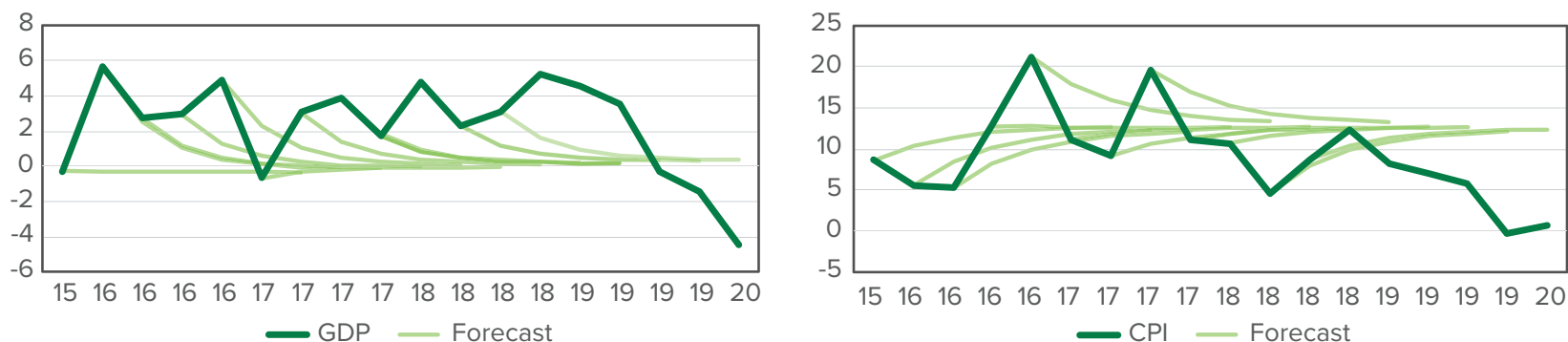

b) MA_TOT
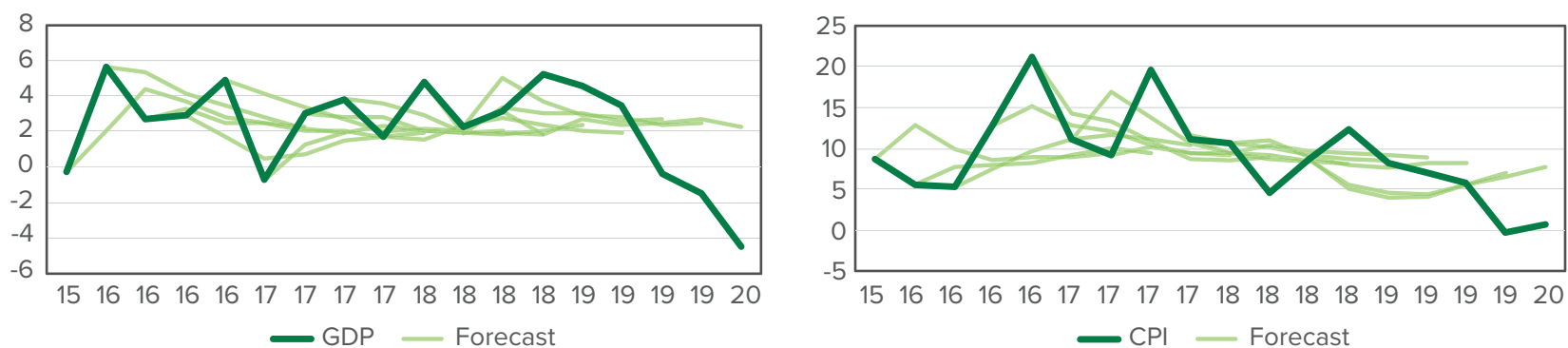

c) MA_P
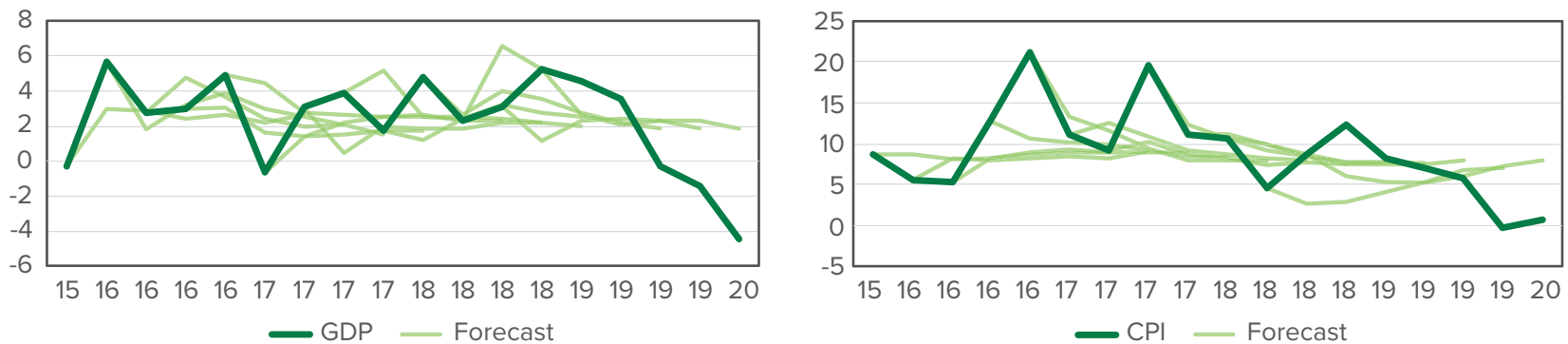

d) $M B$
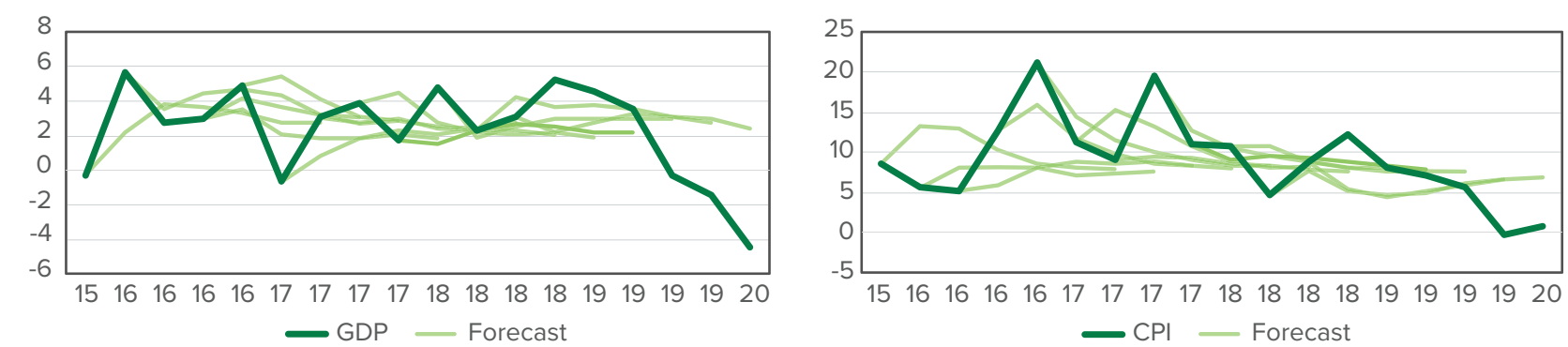

Figure C.6. Unconditional BVAR and AR1 Forecasts 
a) MA_TOT(cond)
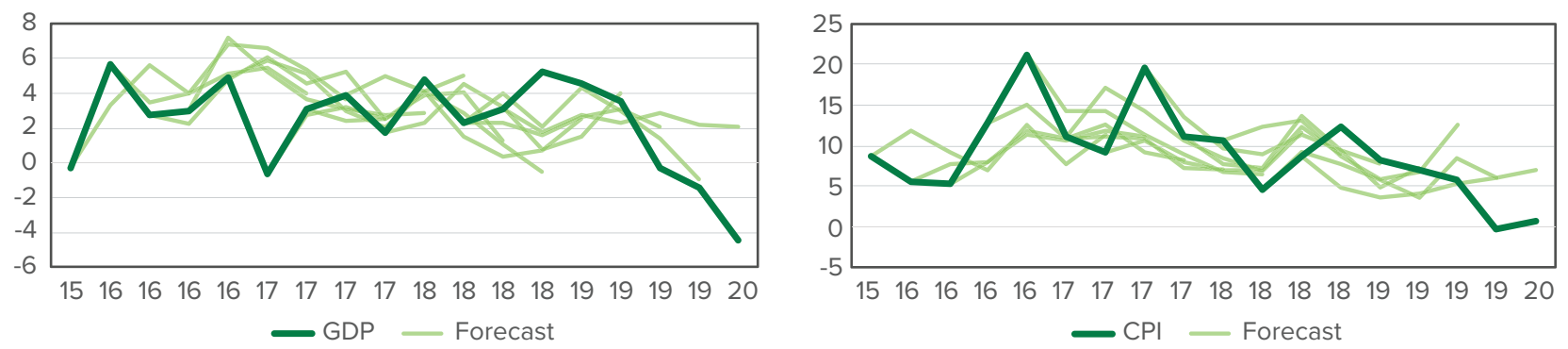

b) QPM
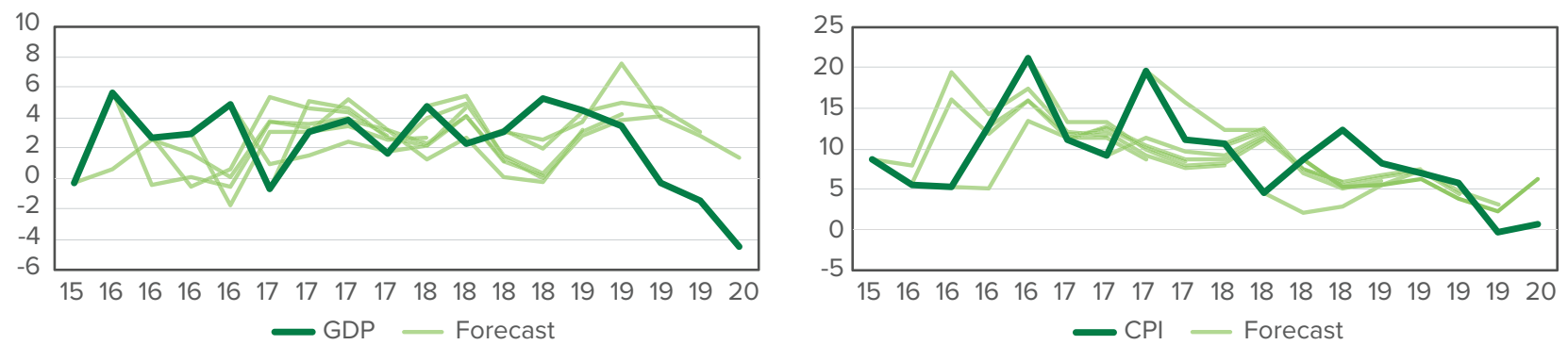

Figure C.7. Conditional BVAR and QPM Forecasts

a) MA_TOT(cond)
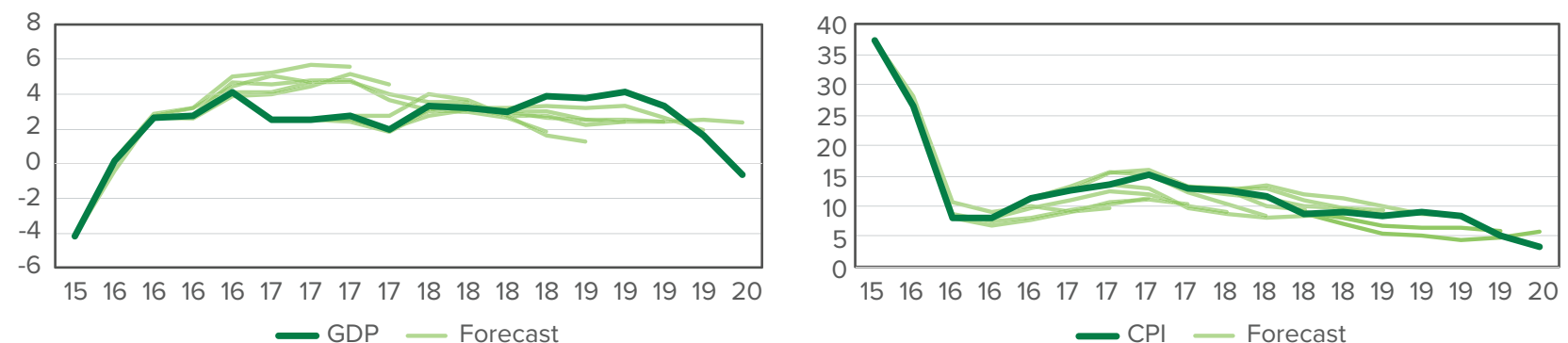

b) NBU
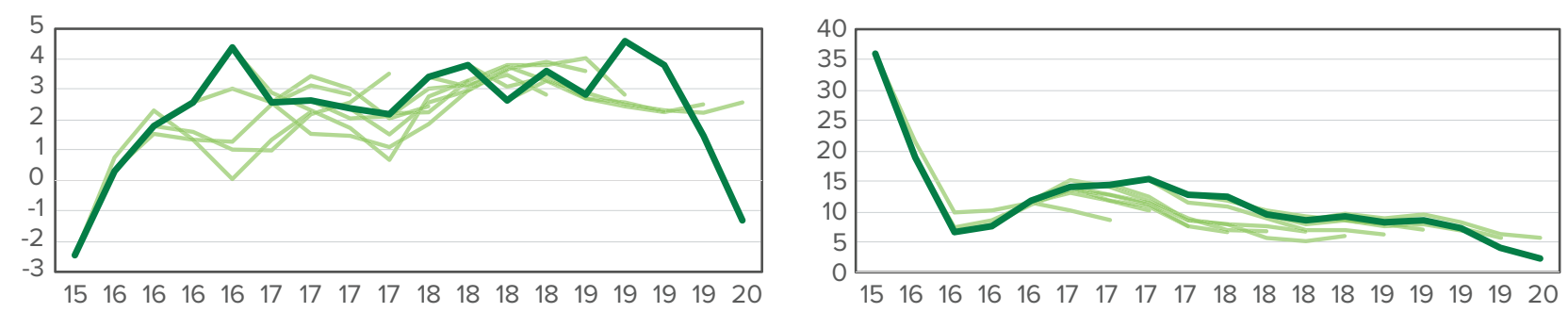

- GDP — Forecast

- $\mathrm{CPI}$ - Forecast

Figure C.8. Conditional BVAR and Official NBU Forecasts for the Indicators on Year-over-Year Basis 